\title{
1 Flutter characteristics of twin-box girder bridges with vertical \\ 2 central stabilizers
}

3 Yongxin Yang ; Rui Zhou ${ }^{\text {a }}$ Y Yaojun Ge ${ }^{\mathrm{a}}$; Xiaojie Zou ${ }^{\mathrm{a}}$; Lihai Zhang

$4 \quad{ }^{a}$ State Key Lab for Disaster Reduction in Civil Engineering, Tongji University, Shanghai 200092, China

$5 \quad{ }^{\mathrm{b}}$ Department of Infrastructure Engineering, University of Melbourne, VIC 3010, Australia

6 Abstract:

7 It has been well known that Vertical Central Stabilizers (VCS) have the potential of 8 improving flutter performance of long-span bridges. However, the fundamental flutter 9 mechanisms of VCS are still not fully understood so far. In this study, a series of wind10 tunnel tests involving the combination of six representative heights and four types of VCS 11 were conducted to fundamentally investigate the influence of VCS on flutter performance 12 of twin-box girders with various Slot Width Ratios (SWRs). Experimental results show 13 that the flutter instability of $20 \%$ SWR is significantly sensitive to the height change of 14 VCS, whereas the VCS have little effect on the flutter performance for $80 \%$ and $100 \%$ 15 SWR. In addition, the results from Two-Dimensional Three Degree of freedom (2D-3DOF) 16 flutter analysis demonstrates that aerodynamic damping Part A with reference of flutter 17 derivative $A_{2}{ }^{*}$ makes the greatest contribution to the flutter instability for a $0.8 \mathrm{~h} / \mathrm{H} \mathrm{VCS}$, 18 while the role of Part D with reference of $A_{1}{ }^{*} H_{3}{ }^{*}$ becomes critical for a short VCS (i.e. the 19 ratio of $\mathrm{h} / \mathrm{H}$ is less than 0.2 ). Besides, the results of Computational Fluid Dynamics 20 simulation indicate that the geometry of VCS influence the transforming vortices'

21 structures and pressure distribution under the central slotting. Finally, the modified Selberg 22 formula presented in this study has the capability of predicting the critical flutter speed of 23 twin-box girders with various SWRs and VCS.

24 Keywords: Twin-box girder; vertical central stabilizer; slot width ratio; flutter instability; 25 aerodynamic damping; flow structures; Selberg formula.

\section{1. Introduction}

27 Twin-box girders with a center gap between two girders has been proven to be one of 28 the effective aerodynamic countermeasures for improving the aerodynamic performance of 
29 long-span cable-supported bridges, and so its implementation becomes increasingly 30 popular for long-span, or even super long-span bridges [1,2,3], e.g., Xihoumen Bridge with 31 the main span of $1650 \mathrm{~m}$ (China) and Gwangyang Bridge with the main span of $1545 \mathrm{~m}$ 32 (Korea). Nevertheless, twin-box girders with various Slot Width Ratios (SWRs, for 33 example, the $20 \% \mathrm{SWR}$ refers to $D / B s=0.2$, where $D$ is slot width and $B s$ is the width of two decks) may exhibit different flutter performance [4,5]. Although the maximum growth rate of Critical Flutter Wind Speed $\left(\mathrm{U}_{\mathrm{cr}}\right)$ could reach more than $20 \%$ after slotting for twin36 box girders, the aerodynamic stability of the bridges becomes uncertain when the length of 37 the growing span of the bridge is over certain limit [4,6]. Therefore, the implementation of practicable aerodynamic countermeasures (e.g. Vertical Central Stabilizers (VCS)) 39 becomes necessary for further enhancing the flutter performance of super long-span 40 bridges.

VCS could play an important role in the airflow separation and have been applied in 42 many long-span bridges with different geometrical shapes to improve flutter performance. 43 For example, the Akashi Kaikyo Bridge (the length of the longest span is $1991 \mathrm{~m}$ ) with a $442.15 \mathrm{~m}$ height VCS installed in the centerline of the truss-type stiffening girder [7] and the 45 Runyang Yangtze River Bridge (the length of the longest span is $1490 \mathrm{~m}$, China) with a $460.65 \mathrm{~m}$ height VCS on the top of the closed box girder [8]. Based on the numerical 47 simulation, VCS have been verified to be an effective aerodynamic measure to improve 48 the flutter performance of long-span bridges either with an open cross section or with a 49 streamlined box cross section [9]. The results from wind tunnel tests also confirm that both 50 the VCS on the top of two-isolated-girder section and box girders with cantilevered slabs 51 could increase the $\mathrm{U}_{\mathrm{cr}}$ by approximately $11 \%$ [10]. Moreover, the flutter performance of 52 twin-box girders could be significantly improved when installing a reasonable scheme of 53 VCS $[11,12,13]$.

54 Over the last decades, a lot of research work has been carried out to investigate the 55 control effectiveness of VCS on the flutter performance of long-span bridges with box 56 girders. It has been found that the flutter control effect of VCS is closely related to the 57 height and location of VCS. The flutter performance of box girders will decrease if the 58 height of VCS exceeds a critical limit [10]. The installation of central stabilizer on the top 
of a box girder (Type A) appears to be one of the best ways of stabilizing box girders

60 aerodynamically, while the optimal height of VCS depends on the types of VCS (three

61 types of stabilizers were studied in present study: Type A-only one VCS installed on the

62 top of deck; Type B - only one VCS installed on the bottom of deck; Type AB - one VCS

63 installed on the top of deck, while another one installed below the bottom of deck) [8].

64 Flutter performance of a multi-box girder section gradually improves with the increase of

65 the height of VCS on the top of girder section, whereas the $\mathrm{U}_{\mathrm{cr}}$ decreases when the height

66 of VCS is greater than $0.5 \mathrm{~h} / \mathrm{H}$ [14]. As for the twin-box girders, Type $\mathrm{C}$ has the best flutter-

67 controlling effect for a twin-box girder among three basic types of Type A, B and C (i.e.

68 Type $\mathrm{C}$ - installing VCS under the central slotting), and the combination schemes of VCS

69 (Type $\mathrm{A}+\mathrm{B}$ and Type $\mathrm{C}+\mathrm{B}$ ) are more effective with the about $15 \%$ growth rate of $\mathrm{U}_{\mathrm{cr}}[10]$.

70 However, the control effect of VCS with various positions and configurations flutter

71 performance for twin-box girder bridges with various SWR is still not well understood.

72 Therefore, further research work on identifying the optimal height and location of VCS for

73 twin-box girder bridges with various SWR is required.

74 To further understand the role of VCS in the improvement of flutter performance, the 75 present study mainly focuses on the flutter instability taking into consideration flutter 76 derivatives and the coupling effects of heaving and torsional degree, as well as the effect 77 of flow structures around girders. Matsumoto et al. [15] proposed a new approach in 78 studying the flutter instability of flutter branches. Their results suggested that the 79 controlling flutter derivatives is a way of controlling the flutter mechanism. Chen, et al.

80 [16] found that the aerodynamic damping with the reference of flutter derivative $A_{2}{ }^{*}$ is the 81 most important stabilizing term among five flutter derivatives, and the use of VCS could 82 produce a higher level of heaving degree participation and greater critical wind speed for 83 a truss- girder section. In addition, many studies have successfully employed the 84 Computational Fluid Dynamics (CFD) technique for simulating the flow structures around 85 oscillating bridge sections with the aim of exploring the flutter mechanism and predicting 86 the critical flutter wind speed [17-23]. CFD simulation results based on Random Vortex 87 Method also showed that the $\mathrm{U}_{\mathrm{cr}}$ could be increased by using VCS since the strength of the 88 large vortices' structure become weakened and its rhythmic motion is destroyed [9].CFD 
simulation results showed that the VCS control the stream around the girder as well as the vortex generation [16]. However, the relevant studies on the flutter mechanism of twin-box girders with VCS are limited and need to be further investigated. In the present study, we aim to investigate the flutter characteristics of twin-box girders with various schemes of SWRs and VCS. Firstly, wind tunnel tests were firstly conducted to demonstrate the influence of bridge geometry in the flutter performance of twin-box girders with six representative height and four types of VCS. The measured $\mathrm{U}_{\mathrm{cr}}$ corresponding to these schemes of aerodynamic countermeasures, such as different combination of five SWRs and VCS, were analyzed and compared, respectively. Secondly, a Two-Dimensional Three Degree of Freedom (2D-3DOF) flutter analysis method has been adopted to quantify the flutter mechanism with regard to aerodynamic damping and DOF participation level of three types of VCS. Accordingly, the velocity filed and pressure distributions from CFD simulations were used to further understand the aerodynamic behavior of twin-box girder bridges with various VCS. In addition, both the Lorentz function and Sine function were employed to estimate the correction coefficient of the modified Selberg formula, which is of importance for estimating the $U_{c r}$ of twin-box girders with various SWRs and VCS.

\section{Flutter performance of twin-box girders with VCS}

106

\subsection{Experimental set-up}

The measurement of the $U_{c r}$ of twin-box girders with different combination schemes of SWR and VCS is the purpose of this experimental investigation. As shown in Fig. 1(a) and (b), a series of 1:80 simplified section models of twin-box girders without consideration of the deck secondary structures were performed in the TJ-1 Wind Tunnel of Tongji University to accommodate the size of sectional models and testing section. Since the SWR plays an important role in the aerodynamic performance of twin-box girder bridges [4,5], spring-supported rigid sectional models with five representative cases of SWR (i.e. $D / B_{s}=0.2,0.4,0.6,0.8$, and 1.0 ) were used in the testing to assess the control effectiveness of VCS on the flutter instability in twin-box girders bridges. In addition, to systematically investigate the influence of different heights of VCS on the flutter instability of the bridges, six representative relative height $(\mathrm{h} / \mathrm{H})$ of $\mathrm{VCS}(\mathrm{i} . \mathrm{e} . \mathrm{h} / \mathrm{H}=0,0.2,0.4,0.6$, 
1180.8 and 1.0) were selected for Types A, B, AC and BC (Fig. 1(c) and Table 2). The values 119 of structural parameters used in the testing, such as geometric dimensions, mass 120 characteristics, fundamental frequencies and structural damping, are given in Table 1. It 121 should be mentioned that, the adjustable additional mass on the section models were 122 adopted to make the equivalent mass characteristics consistent in all testing cases.

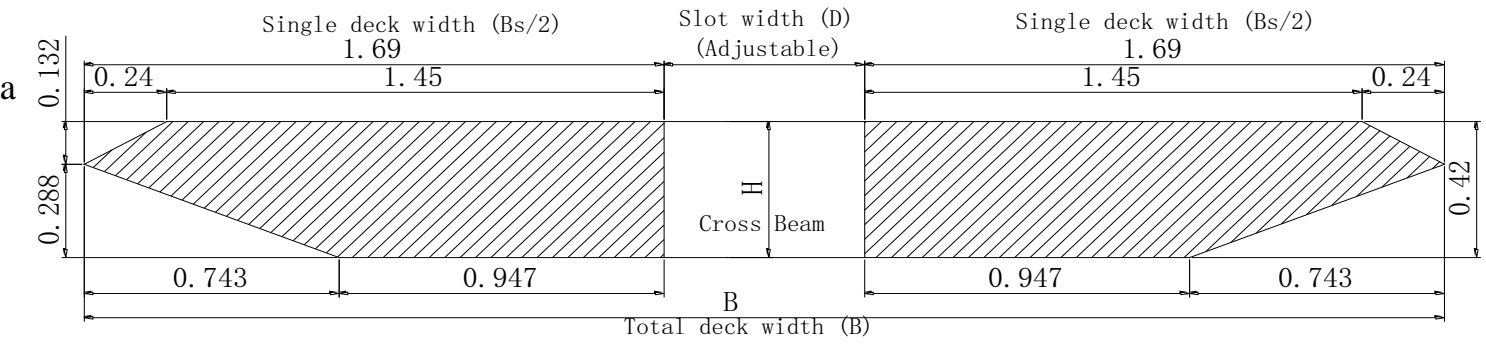

$\mathrm{b}$

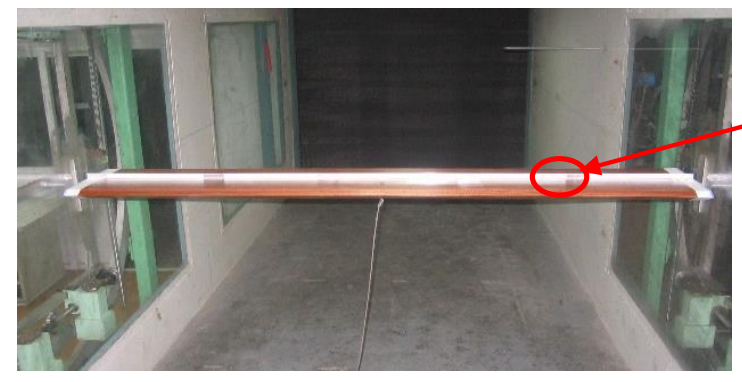

Vertical central stabilizer (VCS) $\mathrm{c}$ Two basic Types Two combination Types E.
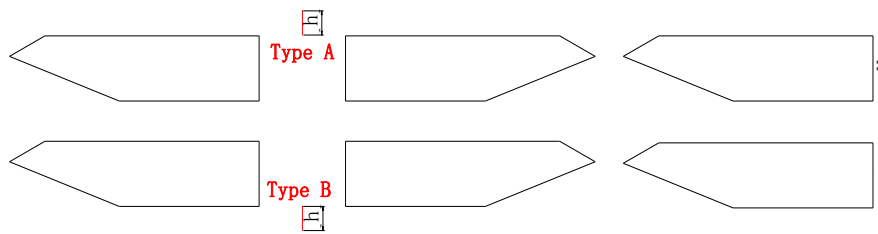
Type AC
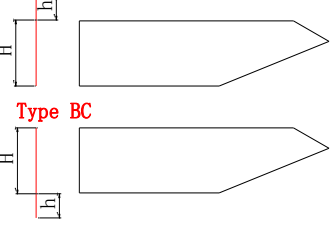

Type $\mathrm{BC}$

다

I

Fig. 1. Flutter tests of twin-box girders with central stabilizers: (a) Sectional model diagram (unit: m); (b) Setup of springs-supported sectional models; and (c) four types of VCS

\section{Table 1}

127 Parameters of sectional model of twin-box girders

\begin{tabular}{cccccccc}
\hline & Properties & \multicolumn{7}{c}{ Slot ratio } \\
\cline { 3 - 8 } & & $\mathbf{0 \%}$ & $\mathbf{2 0 \%}$ & $\mathbf{4 0 \%}$ & $\mathbf{6 0 \%}$ & $\mathbf{8 0 \%}$ & $\mathbf{1 0 0 \%}$ \\
\hline \multirow{2}{*}{$\begin{array}{c}\text { Geometric } \\
\text { scale }\end{array}$} & Length $L / m$ & 1.7 & 1.7 & 1.7 & 1.7 & 1.7 & 1.7 \\
& Width $B / m$ & 0.338 & 0.406 & 0.473 & 0.541 & 0.608 & 0.676 \\
& Height $H / m$ & 0.042 & 0.042 & 0.042 & 0.042 & 0.042 & 0.042 \\
\hline \multirow{2}{*}{$\begin{array}{c}\text { Equivalent } \\
\text { mass }\end{array}$} & $\begin{array}{c}m / \mathrm{kng} / \mathrm{m} \text { length } \\
\text { Mass moment of }\end{array}$ & 4.406 & 4.406 & 4.406 & 4.406 & 4.406 & 4.406 \\
& $\begin{array}{c}\text { Mnertia/unit length } \\
I_{m} / \mathrm{kg} \cdot \mathrm{m}^{2} / \mathrm{m}\end{array}$ & 0.244 & 0.244 & 0.244 & 0.244 & 0.244 & 0.244 \\
\hline \multirow{2}{*}{ Frequency } & Vertical $f_{h} / \mathrm{Hz}$ & 1.343 & 1.343 & 1.343 & 1.343 & 1.343 & 1.343 \\
& Torsional $f_{t} / \mathrm{Hz}$ & 2.660 & 2.660 & 2.660 & 2.660 & 2.660 & 2.660 \\
\hline & & & & & & & 5
\end{tabular}




\begin{tabular}{cccccccc}
\hline \multirow{2}{*}{$\begin{array}{c}\text { Damping } \\
\text { ratio }\end{array}$} & Vertical $\xi_{h} / \%$ o & 5 & 5 & 5 & 5 & 5 & 5 \\
\hline
\end{tabular}

Table 2 shows a total of 240 test cases under three wind attack angles (i.e. $+3^{\circ}, 0^{\circ}$ and

$129-3^{\circ}$ ), in which Type A and Type B are two basic types which are the first focus of this study.

130 The smaller SWR (i.e. $20 \%$ and 40\%) are common ratios in the existing twin-box girders

131 bridges and their flutter performance are better than those with larger SWR (i.e. 80\% and

$132100 \%$ ) [4]. Therefore, two combination types of Type AC (both on the top and under the

133 central slotting) and Type BC (both below the bottom and under the central slotting) are

134 mainly focus on two small SWR (i.e. $20 \%$ and $40 \%$ ). In this study, a naming convention

135 was adopted for all testing cases, for example S02_A02 denotes case Type A with 20\%

136 SRW and $0.2 \mathrm{~h} / \mathrm{H}$ of VCS.

137 Table 2

138 Testing cases of flutter performance of twin-box girders with various SWR and VCS

\begin{tabular}{|c|c|c|c|c|c|c|c|}
\hline Name & SRW & $\begin{array}{c}\text { Location of } \\
\text { VCS }\end{array}$ & $\begin{array}{l}\text { Relative height } \\
\text { of VCS }(\mathrm{h} / \mathrm{H})\end{array}$ & $\begin{array}{c}\text { Height } \\
\text { of } \\
\text { VCS } \\
\text { h (m) }\end{array}$ & $\begin{array}{c}\text { Slot } \\
\text { width } \\
\text { D (m) }\end{array}$ & $\begin{array}{l}\text { Total } \\
\text { width } \\
\text { B (m) }\end{array}$ & $\begin{array}{c}\text { Wind attack } \\
\text { angle }\left(^{\circ}\right)\end{array}$ \\
\hline S02_A00 & & & 0 & 0 & 0 & 0.338 & $0, \pm 3$ \\
\hline S02_A02 & & Type A, & 0.2 & 0.0084 & 0.068 & 0.406 & $0, \pm 3$ \\
\hline S02_A04 & $200 \%$ & Type B, & 0.4 & 0.0168 & 0.135 & 0.473 & $0, \pm 3$ \\
\hline S02_A06 & $20 \%$ & Type AC & 0.6 & 0.0252 & 0.203 & 0.541 & $0, \pm 3$ \\
\hline S02_A08 & & & 0.8 & 0.0336 & 0.270 & 0.608 & $0, \pm 3$ \\
\hline S02_A10 & & & 1.0 & 0.0420 & 0.338 & 0.676 & $0, \pm 3$ \\
\hline S04_A00 & & & 0 & 0 & 0 & 0.338 & $0, \pm 3$ \\
\hline S04_A02 & & Type A, & 0.2 & 0.0084 & 0.068 & 0.406 & $0, \pm 3$ \\
\hline S04_A04 & $100 \%$ & Type B, & 0.4 & 0.0168 & 0.135 & 0.473 & $0, \pm 3$ \\
\hline S04_A06 & $40 \%$ & Type AC & 0.6 & 0.0252 & 0.203 & 0.541 & $0, \pm 3$ \\
\hline S04_A08 & & & 0.8 & 0.0336 & 0.270 & 0.608 & $0, \pm 3$ \\
\hline S04_A10 & & & 1.0 & 0.0420 & 0.338 & 0.676 & $0, \pm 3$ \\
\hline S06_A00 & & & 0 & 0 & 0 & 0.338 & $0, \pm 3$ \\
\hline S06_A02 & & & 0.2 & 0.0084 & 0.068 & 0.406 & $0, \pm 3$ \\
\hline S06_A04 & $60 \%$ & Type A, & 0.4 & 0.0168 & 0.135 & 0.473 & $0, \pm 3$ \\
\hline S06_A06 & $60 \%$ & Type B & 0.6 & 0.0252 & 0.203 & 0.541 & $0, \pm 3$ \\
\hline S06_A08 & & & 0.8 & 0.0336 & 0.270 & 0.608 & $0, \pm 3$ \\
\hline S06_A10 & & & 1.0 & 0.0420 & 0.338 & 0.676 & $0, \pm 3$ \\
\hline S08_A00 & & & 0 & 0 & 0 & 0.338 & $0, \pm 3$ \\
\hline S08_A02 & & & 0.2 & 0.0084 & 0.068 & 0.406 & $0, \pm 3$ \\
\hline S08_A04 & & Type A, & 0.4 & 0.0168 & 0.135 & 0.473 & $0, \pm 3$ \\
\hline S08_A06 & $80 \%$ & Type B & 0.6 & 0.0252 & 0.203 & 0.541 & $0, \pm 3$ \\
\hline S08_A08 & $80 \%$ & & 0.8 & 0.0336 & 0.270 & 0.608 & $0, \pm 3$ \\
\hline S08_A10 & & & 1.0 & 0.0420 & 0.338 & 0.676 & $0, \pm 3$ \\
\hline S10_A00 & & & 0 & 0 & 0 & 0.338 & $0, \pm 3$ \\
\hline S10_A02 & $100 \%$ & & 0.2 & 0.0084 & 0.068 & 0.406 & $0, \pm 3$ \\
\hline S10_A04 & & Type A, & 0.4 & 0.0168 & 0.135 & 0.473 & $0, \pm 3$ \\
\hline
\end{tabular}




\begin{tabular}{|c|c|c|c|c|c|c|c|}
\hline S10_A06 & & Type B & 0.6 & 0.0252 & 0.203 & 0.541 & $0, \pm 3$ \\
\hline S10_A08 & & & 0.8 & 0.0336 & 0.270 & 0.608 & $0, \pm 3$ \\
\hline S10_A10 & & & 1.0 & 0.0420 & 0.338 & 0.676 & $0, \pm 3$ \\
\hline $\mathrm{S} 02 \_\mathrm{BC} 00$ & & & 0 & 0 & 0 & 0.338 & $0, \pm 3$ \\
\hline $\mathrm{S}^{2} 2_{-}^{-} \mathrm{BC} 02$ & & Type BC & 0.2 & 0.0084 & 0.068 & 0.406 & $0, \pm 3$ \\
\hline $\mathrm{S} 02 \_\mathrm{BC} 04$ & $20 \%$ & & 0.4 & 0.0168 & 0.135 & 0.473 & $0, \pm 3$ \\
\hline $\mathrm{S}^{2} 2_{-} \mathrm{BC} 06$ & & & 0.6 & 0.0252 & 0.203 & 0.541 & $0, \pm 3$ \\
\hline S04_BC00 & & & 0 & 0 & 0 & 0.338 & $0, \pm 3$ \\
\hline $\mathrm{S} 04 \_\mathrm{BC} 02$ & 4007 & Type BC & 0.2 & 0.0084 & 0.068 & 0.406 & $0, \pm 3$ \\
\hline S04_BC04 & $40 \%$ & & 0.4 & 0.0168 & 0.135 & 0.473 & $0, \pm 3$ \\
\hline S04_BC06 & & & 0.6 & 0.0252 & 0.203 & 0.541 & $0, \pm 3$ \\
\hline
\end{tabular}

\subsection{Effects of VCS on critical flutter speed}

140 The objective of this testing phase was to study the influence of different schemes of

141 VCS on the minimum $U_{c r}$ of twin-box girders with various SWR, since the dominant factor 142 of flutter instability is the minimum value of three $U_{\text {cr }}$ corresponding to the attack angles 143 of $+3^{\circ}, 0^{\circ}$ and $-3^{\circ}$, respectively. The lowest $\mathrm{U}_{\mathrm{cr}}$ under three wind attack angles and their 144 corresponding growth rates $(\beta)$ for twin-box girders with six SWR (including the 0\% slot 145 ratio) and six h/H of VCS are illustrated in Fig. 2. It is noted that the growth rates $\beta$ of $U_{c r}$ 146 are calculated by using the equation: $\beta=\left(\mathrm{U}_{\mathrm{cr}}-\mathrm{U}_{\mathrm{cr} 0}\right) / \mathrm{U}_{\mathrm{cr} 0} \times 100 \%$, where $\mathrm{U}_{\mathrm{cr} 0}$ is the value of $147 \mathrm{U}_{\mathrm{cr}}$ without consideration of VCS. It should be noted that the wind attack angle of $+3^{\circ}$ 148 results in the lowest $\mathrm{U}_{\mathrm{cr}}$, and thus represents the most unfavorable condition under wind 149 loading.
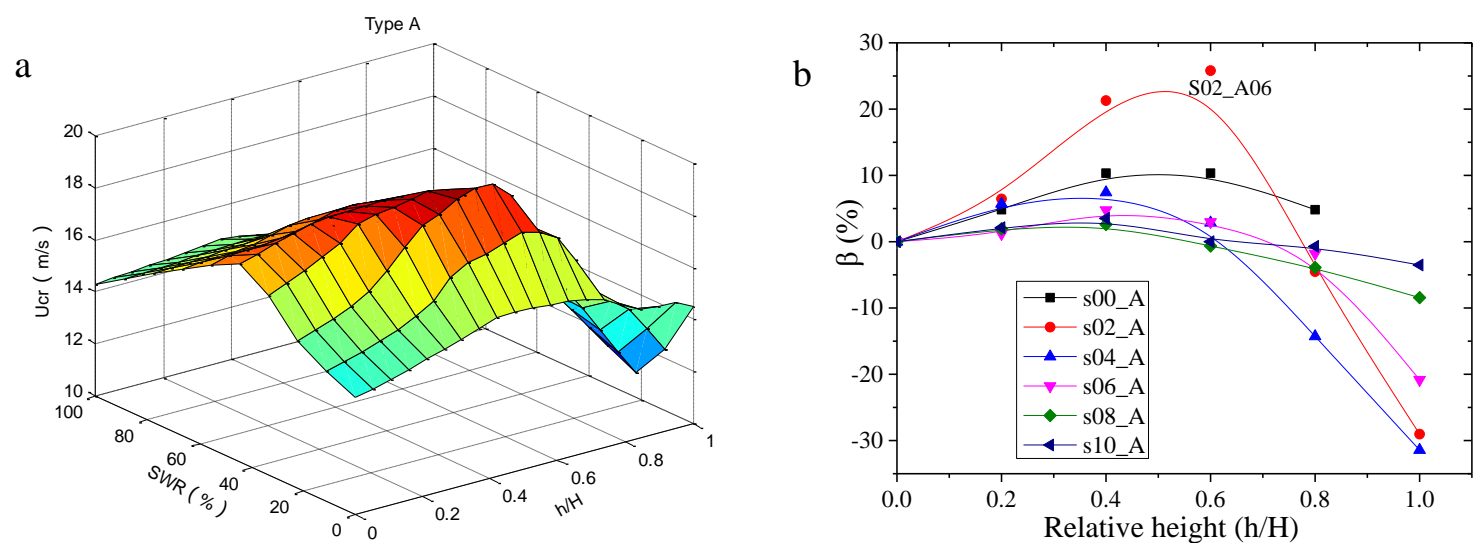

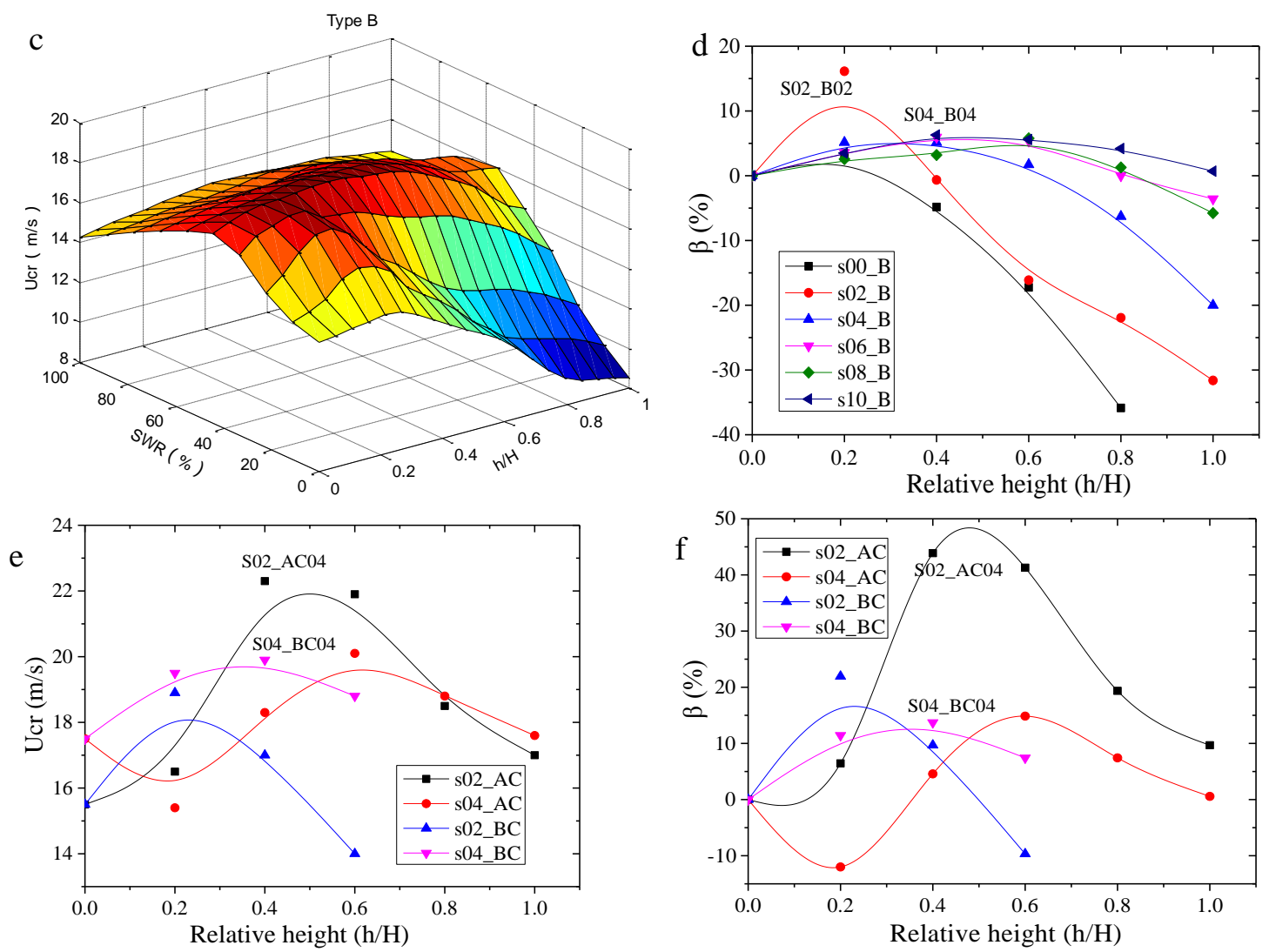

Fig. 2. $U_{c r}$ and $\beta$ of different SWR and VCS: (a) $U_{c r}$ of Type A, (b) $\beta$ of Type $A$, (c) $U_{c r}$ of Type $B$, (d) $\beta$ of Type B, (e) $\mathrm{U}_{\mathrm{cr}}$ of Type $\mathrm{AC}$ and $\mathrm{BC}$, (f) $\beta$ of Type $\mathrm{AC}$ and BC

\subsubsection{Height of central stabilizers}

For Type $A$ and Type $B, U_{c r}$ and their $\beta$ of twin-box girders with $0 \%$ SWR were obtained from the study of Ge et al. 2009, which are defined as two cases (i.e. s00_A and s00_B in Fig.2), respectively. It is interesting that the 0\% SWR of Type B has a rapidly decline along with the increase of the $\mathrm{h} / \mathrm{H}$ of VCS, and thus the Type B has disadvantage contribution to the flutter instability of a twin-box girder with $0 \% \mathrm{SWR}$.

It can be seen from Fig. 2 (a) to (d) that the stabilizing effectiveness of twin-box girders with a certain Type of VCS firstly increases with the increase of $\mathrm{h} / \mathrm{H}$, reaches to an optimal value and then gradually decreases. Noteworthy, the optimal value of $\mathrm{h} / \mathrm{H}$ for different types of VCS is different, e.g. about 0.5 for Type A and 0.2 for Type B. In addition, the growth rate $\beta$ of Type $A$ are negative when the ratio of $h / H$ is over 0.6 , and the $\beta$ for Type $B$ are also negative when the ratio of $h / H$ is greater than 0.4 . As shown in the Fig. 2 (e) and (f), for Type AC, the $U_{c r}$ and their $\beta$ firstly increase with the increase of 
the $\mathrm{h} / \mathrm{H}$ of VCS. In addition, for Type AC with $20 \%$ SWR, the value of $\beta$ could reach as high as $42 \%$ for both 0.4 and $0.6 \mathrm{~h} / \mathrm{H}$ ratios. The relationship between $\beta$ and $\mathrm{h} / \mathrm{H}$ demonstrates that the optimal $\mathrm{h} / \mathrm{H}$ for Type $\mathrm{BC}$ is around 0.4 . As a result, the best flutter performance for four types VCS is the case of s02_A06, s04B_04, s02AC_04, s04BC_04, respectively. In general, the optimal height of VCS is around $0.4 \mathrm{~h} / \mathrm{H}$, which could effectively improve the flutter performance of a twin-box girder bridge.

\subsubsection{Influence of slot width ratios}

As for the influence of SWR on the flutter instability, both the $U_{\text {cr }}$ and $\beta$ resulted from $20 \%$ SWR are significantly sensitive to the heights change of VCS among six SWR. As shown in Fig. 2 (b), (d) and (f), the 20\% SWR leads to the largest positive growth rate for relatively small $\mathrm{h} / \mathrm{H}$, such as the $25.8 \%$ of the $0.6 \mathrm{~h} / \mathrm{H}$ Type $\mathrm{A}$ and $16 \%$ of the $0.2 \mathrm{~h} / \mathrm{H}$ Type B. The largest growth rates of Type A and B with the $1.0 \mathrm{~h} / \mathrm{H}$ are about $-30 \%$ when the SWR is $20 \%$. In addition, the $\mathrm{U}_{\mathrm{cr}}$ of $60 \%$ slot ratio rapidly decreases after the ratio of $\mathrm{h} / \mathrm{H}$ of Type A is over 0.6. Particularly, Types A and B have limited influence on the flutter performance when the SWR is $80 \%$ or $100 \%$, regardless of the relative height of VCS.

For Type AC, the values of $\beta$ for the $20 \%$ SWR are positive and larger than that of the $40 \%$ SWR. This indicates that Type AC is the best choice for the $20 \%$ SWR, especially when $\mathrm{h} / \mathrm{H}$ ratio of VCS is 0.4 or 0.6 . However, for Type $\mathrm{BC}$, the values of $\mathrm{U}_{\mathrm{cr}}$ of the $40 \%$ SWR are much larger than those with the 20\% SWR. This indicates that Type BC is the best choice for the $40 \%$ SWR. In a word, the control effects of twin-box girders with VCS are closely related to the SWR, but the influence of SWR on flutter instability of twin-box girders gradually decreases with the increase of SWR.

\subsubsection{Types of central stabilizers}

The flutter control effectiveness of twin-box girders with four types of VCS are different from each other. Fig. 3 (a) and (b) show the growth rate $\beta$ of the $20 \%$ and $40 \%$ SWR with four types of VCS, respectively.

Regarding to the 20\% SWR, the control effects of Types AC and A are better than those of Types B and BC for higher ratios of $\mathrm{h} / \mathrm{H}$. Especially, Type AC can significantly enhance the $\mathrm{U}_{\text {cr }}$ when the $\mathrm{h} / \mathrm{H}$ is larger than 0.2. However, the $\beta$ of Types B and BC with the $0.2 \mathrm{~h} / \mathrm{H}$ are larger than those of Types $\mathrm{AC}$ and $\mathrm{A}$, respectively. Consequently, a smaller 
h/H (i.e. 0.2) of VCS installed at the bottom of central slotting could improve the flutter instability, and a high h/H (i.e. 0.4 to 1.0 ) of VCS installed at the top of slotting has positive effects. On the other hand, the $\beta$ values of Type AC are generally larger than that of Type A, while the $\beta$ values of Type BC are larger than that of Type B. This indicates that the control effects of Types AC and BC are better than that of Types A and B. In summary, the Type AC produces the best flutter performance for a twin-box girder with $20 \%$ SWR, followed by Type A, while Type B results in the worst outcomes.

As for the $40 \% \mathrm{SWR}$, the $\beta$ value of Type $\mathrm{BC}$ is the largest among the four types when the ratios of $\mathrm{h} / \mathrm{H}<0.6$, while the $\beta$ value of Type $\mathrm{AC}$ becomes the largest when the ratios of $\mathrm{h} / \mathrm{H}>0.6$. Moreover, the control effect of Type $\mathrm{BC}$ is also better than that of Type $\mathrm{B}$, while the effect of Type AC is better than that of Type A, expect for the $0.2 \mathrm{~h} / \mathrm{H}$ of Type AC. Thus, two combination types (i.e. Type AC and Type BC) produces better outcomes than two basic types (i.e. Type A and Type B). Therefore, Type AC with a higher ratio of $\mathrm{h} / \mathrm{H}$ is a recommended flutter countermeasure for twin-box girders bridges.
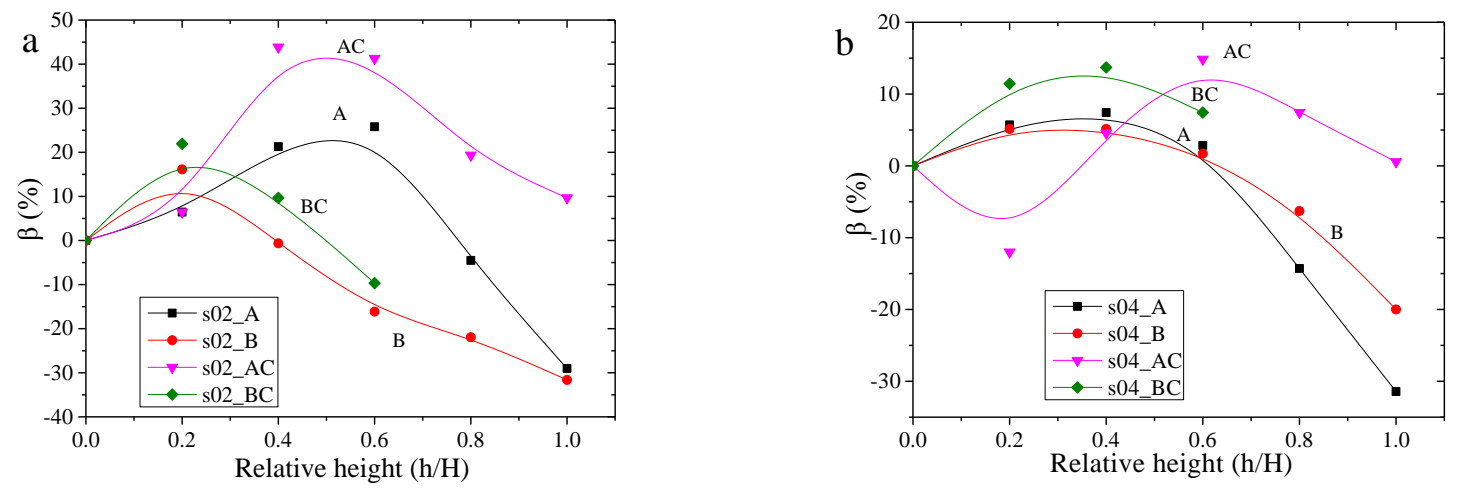

Fig. 3. $\beta$ of different types of VCS: (a) $20 \%$ slot ratio, and (b) $40 \%$ slot ratio

\section{Theoretical analysis of stabilizing mechanism}

A two-dimensional three-degree-of-freedom (2D-3DOF) flutter analysis method was developed to quantify the effects of flutter derivatives, aerodynamic damping, and flutter modality on flutter performance $[4,8]$. In this study, 2D-3DOF was applied to theoretically analyze the stabilization mechanism of twin box girders under various VCS. Three typical types, including the $20 \%$ SWR for Types A and B and the $40 \%$ SWR for Type AC, were 
220 given as the example, and the stabilization mechanism of the three types with different $\mathrm{h} / \mathrm{H}$ 221 ratios were mainly investigated in this study.

\subsection{Total damping ratios and Flutter derivatives}

Regarding to heaving-torsional coupled flutter, the most important aerodynamic damping component is torsional damping ratio. The total damping ratios and typical eight flutter derivatives of twin-box girders using different VCS were calculated under the unfavorable wind attack angle of $+3^{\circ}$ [24-27]. The total torsional damping ratios $\left(\xi_{t}\right)$ and $A_{2}{ }^{*}$ are compared in Fig. 4.

It can be seen that all of total torsional damping ratios initially increase with the increase of wind speed, peak values, then rapidly decrease, and finally shift from the positive to negative territory on the flutter onset. Especially, the values of $\xi_{t}$ of the $20 \%$

231 SWR with 0.4 and $0.6 \mathrm{~h} / \mathrm{H}$ (Type A) are smaller than those without VCS when the wind 232 speed (U) is less than $14 \mathrm{~m} / \mathrm{s}$. However, when $\mathrm{U}$ is greater than $14 \mathrm{~m} / \mathrm{s}$, the values of $\xi_{t}$ of 233 these two $\mathrm{h} / \mathrm{H}$ ratios (i.e. 0.4 and 0.6 ) are larger than those without VCS. The $\xi_{t}$ of the $20 \%$ SWR with $0.2 \mathrm{~h} / \mathrm{H}$ (Type B) are larger than those without VCS, when U> $12 \mathrm{~m} / \mathrm{s}$. The

235 variation curves of the $\xi_{t}$ of the $40 \% \mathrm{SWR}$ with $0.4 \mathrm{~h} / \mathrm{H}$ (Type AC) constantly increase 236 to a peak value at $\mathrm{U}=17 \mathrm{~m} / \mathrm{s}$ which exceeds the value without VCS, and then becomes 237 negative at a higher wind speed.

238 The value of $A_{2}{ }^{*}$ generally decreases with the increase of wind speed. After installing 239 a relatively short VCS (i.e. 0.2 to $0.6 \mathrm{~h} / \mathrm{H}$ ), the absolute value of $A_{2}{ }^{*}$ becomes smaller than 240 those without VCS. Different from the trend of $A_{2}{ }^{*}$ for small $\mathrm{h} / \mathrm{H}$ ratios, all the absolute 241 values of $A_{2}{ }^{*}$ for the Type A with $0.8 \mathrm{~h} / \mathrm{H}$ are larger than those without VCS.

242

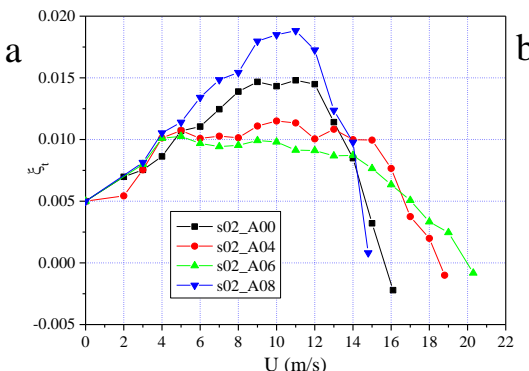

$\mathrm{d}$
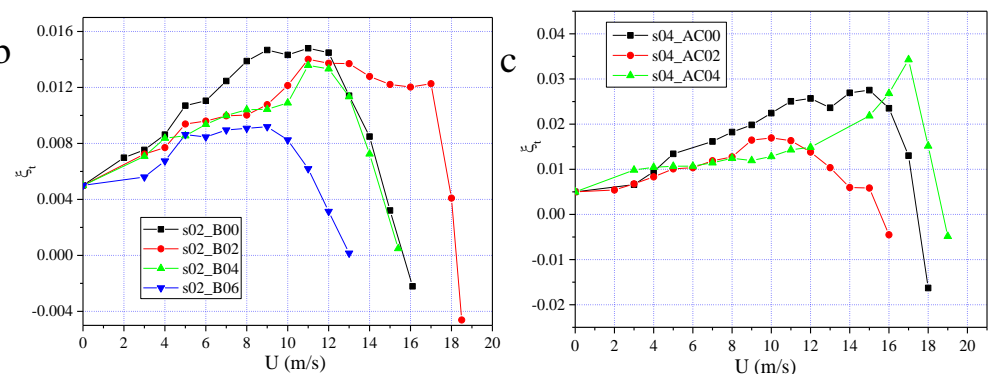

f 

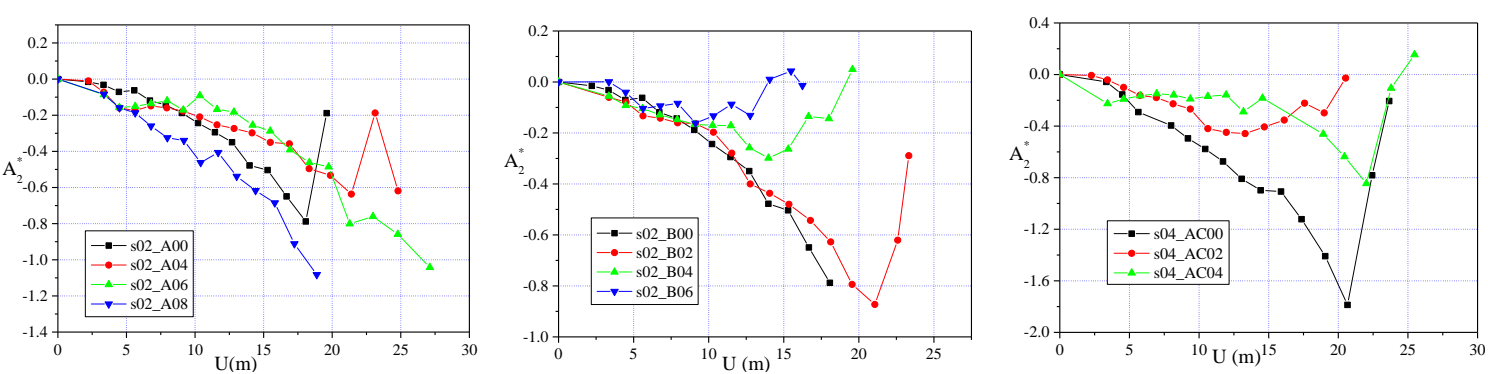

244 Fig. 4. Total torsional damping ratios and flutter derivatives of three types VCS: (a) $\xi_{t}$ of Type A, (b) $\xi_{t}$ of Type B, 245 (c) $\xi_{t}$ of Type AC, (d) $A_{2}{ }^{*}$ of Type A, (e) $A_{2}{ }^{*}$ of Type B, and (f) $A_{2}{ }^{*}$ of Type AC

\section{$246 \quad 3.2$ Aerodynamic damping ratios}

For two-degree-of-freedom (2-DOF) vibration, aerodynamic damping ratios in 248 torsion can be represented by the summation of five parts in Eq. $1[4,8]$, where $\Omega_{i j}$ is the 249 dimensionless equivalent frequency between two motions; $\theta_{i j}$ is phase lag between two 250 motions; $m_{h}$ and I are are mass and mass moment of inertia in the corresponding DOF 251 including heaving $(h)$, swaying $(p)$ and torsion $(\alpha)$. It should be noted that the swaying 252 DOF are not considered in the 2-DOF vibration. Fig. 5 shows the change curves of these 253 five parts (labeled A to E) for twin-box girders with different $\mathrm{h} / \mathrm{H}$ ratios of VCS.

$$
\begin{aligned}
A & \Leftrightarrow-1 / 2 \cdot \rho B^{4} / I \cdot A_{2}^{*} \\
B & \Leftrightarrow-\rho^{2} B^{6} / 2 m_{h} I \cdot \Omega_{h \alpha} \cdot A_{1}^{*} H_{2}^{*} \cos \left(\theta_{\alpha h}+\frac{3}{2} \pi\right) \\
C & \Leftrightarrow \rho^{2} B^{6} / 2 m_{h} I \cdot \Omega_{h \alpha} \cdot A_{4}^{*} H_{2}^{*} \sin \left(\theta_{\alpha h}+\frac{3}{2} \pi\right) \\
D & \Leftrightarrow-\rho^{2} B^{6} / 2 m_{h} I \cdot \Omega_{h \alpha} \cdot A_{1}^{*} H_{3}^{*} \cos \theta_{\alpha h} \\
E & \Leftrightarrow \rho^{2} B^{6} / 2 m_{h} I \cdot \Omega_{h \alpha} \cdot A_{4}^{*} H_{3}^{*} \sin \theta_{\alpha h}
\end{aligned}
$$



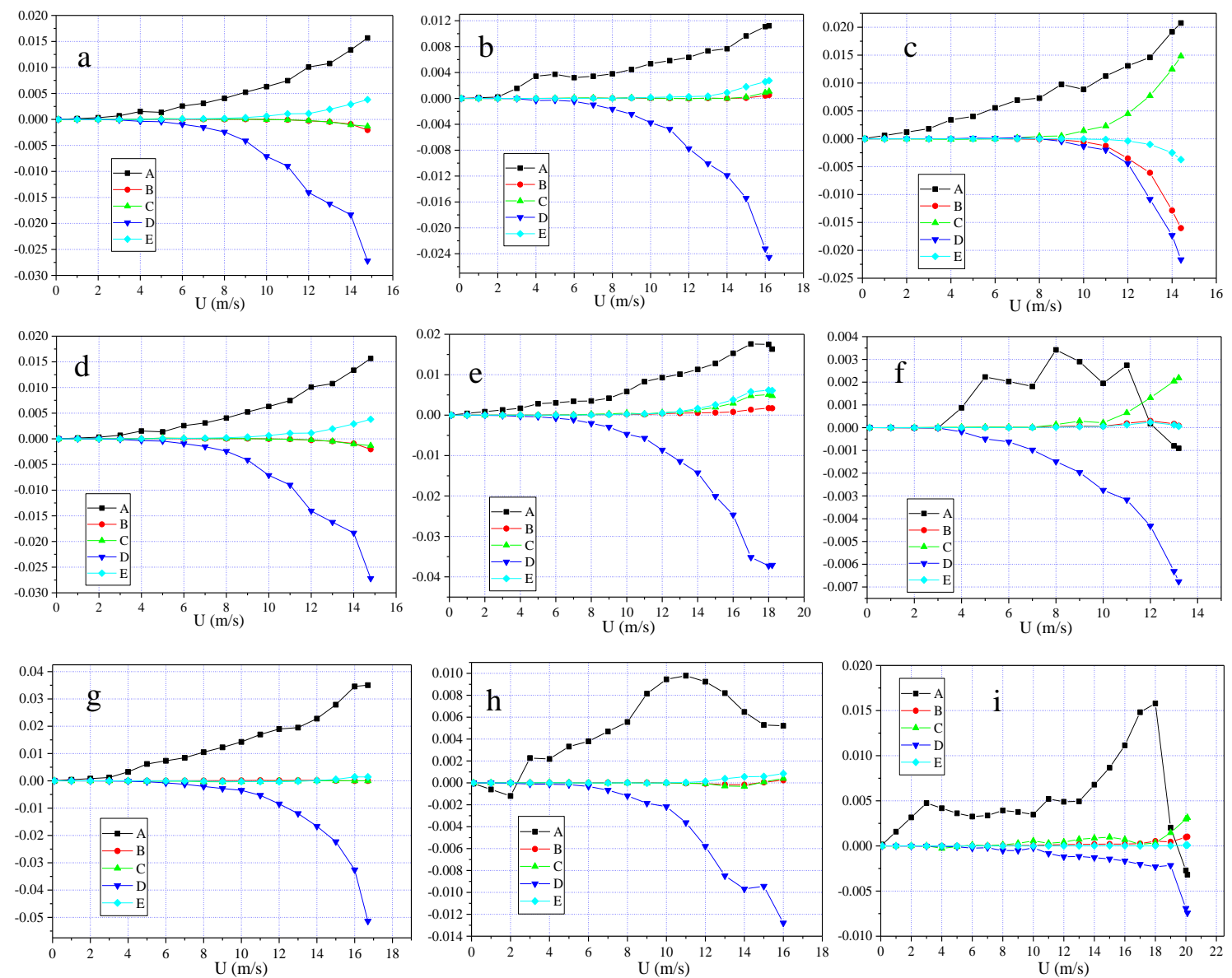

Fig. 5. Aerodynamic damping parts of VCS: (a) $0 \mathrm{~h} / \mathrm{H}$ Type A, (b) $0.4 \mathrm{~h} / \mathrm{H}$ Type A, (c) $0.8 \mathrm{~h} / \mathrm{H}$ Type A, (d) $0 \mathrm{~h} / \mathrm{H}$ Type

B, (e) $0.2 \mathrm{~h} / \mathrm{H}$ Type B, (f) $0.6 \mathrm{~h} / \mathrm{H}$ Type B, (g) $0 \mathrm{~h} / \mathrm{H}$ Type AC, (h) $0.2 \mathrm{~h} / \mathrm{H}$ Type AC, and (i) $0.4 \mathrm{~h} / \mathrm{H}$ Type AC

It can be seen from Fig. 5 that Part D (with a reference of coupling flutter derivatives $\left.A_{1}{ }^{*} H_{3}{ }^{*}\right)$ which has a negative value, monotonically decrease with the increase of $U$, and so has the greatest negative effect on aerodynamic stability among five parts, especially for the $\mathrm{h} / \mathrm{H}$ ratios 0.2 and 0.4 . Consequently, the negative aerodynamic damping resulting from Part D mainly drives the overall oscillating structure into flutter onset condition when installing smaller h/H of VCS. In contrast, Part B, Part C and Part E also have little influence on aerodynamic stability for smaller $\mathrm{h} / \mathrm{H}$ of VCS. Part A (with a reference of flutter derivatives $A_{2}{ }^{*}$ ) which is a positive component, generally increases with the increase of $U$, and therefore makes the greatest contribution to the aerodynamic stability for the 0.8 $\mathrm{h} / \mathrm{H}$ of VCS. The absolute values of Part D are the larger than those of Part A for the smaller height VCS (i.e. $0 \mathrm{~h} / \mathrm{H}$ and $0.2 \mathrm{~h} / \mathrm{H}$ ), while the absolute values of Part A are close to those of Part D for the larger height VCS (i.e. $0.8 \mathrm{~h} / \mathrm{H})$. 
Fig.5 (c) and (f) show that Part B and Part C generally increase with the increase of

$273 \mathrm{~h} / \mathrm{H}$ of VCS. Although Part B and C are more likely to have some positive effect on the 274 aerodynamic stability for relatively high VCS due to the increase of flutter derivatives $\mathrm{H}_{2}{ }^{*}$, 275 the energy of the positive aerodynamic damping produced by Part $\mathrm{C}$ could balance the 276 energy of the negative aerodynamic damping produced by Part B. Therefore, both Part A 277 and Part D in torsional motion also play an important role in maintaining the flutter stability 278 of a girder with VCS, most importantly Part A and Part D become critical in the flutter 279 instability for larger and smaller h/H of VCS, respectively.

\subsection{DOF participation}

The participation level of heaving and torsional DOF at the point of flutter onset, namely the flutter modality, has been used to investigate the role of each DOF plays in structural motion and the coupling effect of DOFs in the flutter oscillation. Based on the 2D-3DOF method, the flutter modality vectors of twin-box girders were calculated and shown in Fig. 6. The numbers from 1 to 3 in Fig. 6 refer to three different h/H ratios of VCS, respectively.
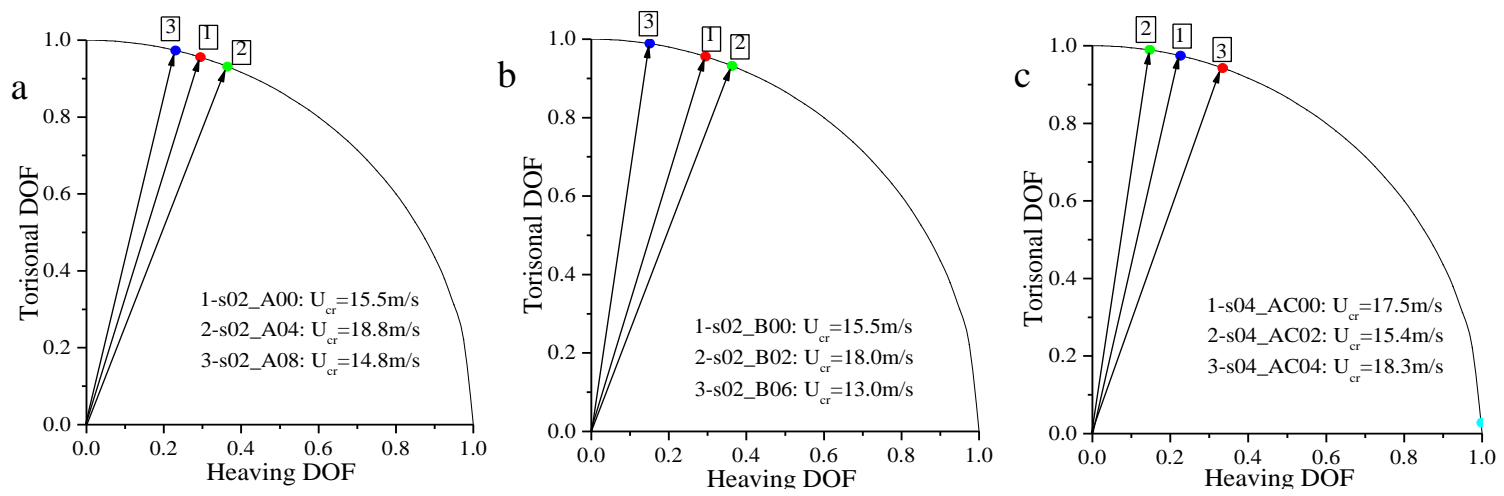

Fig. 6. DOF participation level of three types VCS: (a) Type A, (b) Type B, and (c) Type AC

The position of the flutter modality vector for twin-box girders with VCS indicates that the participation level of heaving motion is considerably high, resulting in strong coupling effects between torsional and heaving motions. With the increase in the $\mathrm{h} / \mathrm{H}$ of Type A and Type B for the $20 \%$ SWR causes the flutter modality vector to move away from the axis of torsional DOF, and approaches to the mid-line between the two axes, 294 indicating stronger coupling effect in flutter oscillation. However, when the h/H of Type 
A and Type B for the $20 \%$ SWR increase to 0.8 and 0.6 , respectively, the modality vector

296 further approaches the axis of torsional DOF, indicating that the participation level of

297 heaving motion decreases and the coupling effect becomes weaker.

298 In addition, for the $40 \%$ SWR with the $0.2 \mathrm{~h} / \mathrm{H}$ (Type AC), the torsional motion

299 becomes dominant in the coupling effect of DOF participation level. Nevertheless, with

300 the $\mathrm{h} / \mathrm{H}$ ratio become to 0.4 , the modality vector further approaches the axis of heaving

301 DOF, implying the heaving participation level and the DOF coupling effect become

302 stronger and stronger. Therefore, the participation level of heaving DOF, which may not

303 monotonic increase with the increase of the $\mathrm{h} / \mathrm{H}$ ratio, has a significant influence in the

304 flutter performance of twin-box girders with VCS. In addition, the increase of contribution

305 from heaving motion associated with negative aerodynamic damping leads to higher

306 critical flutter wind speed when an optimal $\mathrm{h} / \mathrm{H}$ ratio is adopted.

\section{Flow structures simulation}

In this section, the aerodynamic instability mechanism of the VCS was further investigated through CFD simulation in term of instantaneous velocity field and vortex structures.

\subsection{Numerical model}

To determine the flow structures for twin-box girders with VCS, the Smagorinsky subgrid-scale models for fluid-structural coupling and the free oscillation method [5] were used in this study. Based on a finite volume method (FVM), the unstructured grid system incorporating large eddy simulations (LES) modeling was used to discretize the governing Navier-Stokes equations [28]. A stagger mesh discretization method was adopted in the CFD simulation using $\mathrm{C \#}$ based on the unstructured triangular mesh generation technique. Based on the Quadratic Upwind Interpolation of Convective Kinematics of scheme and multidimensional interpolation algorithm, a multidimensional quadratic mixed interpolation scheme in space was adapted. A time marching procedure was performed by the fourth-order Runge-Kutta method. 
The overall unstructured grid system with the computational region of $75 \mathrm{~B} \times 50 \mathrm{~B}$ rectangle is described in Fig.7. The wall function is adopted for the wall boundaries. The maximum Courant number $\mathrm{C}_{\text {conv }}$ is about 0.4 for the $20 \%$ SWR with $0.6 \mathrm{~h} / \mathrm{H} \mathrm{VCS}$. The minimum and maximum values of $\mathrm{y}+$, representing the points close to the structure and the wall, are in the range of about 1.0 and 50, respectively. The time step was set at $0.001 \mathrm{~s}$. The Reynolds number was around 5000 at the flutter onset. A steady uniform flow velocity was applied at the inlet boundary, and an opening pressure condition was given at the outlet boundary. In addition, symmetry condition was used for top and bottom surfaces of the domain. The comparison results of $U_{\mathrm{cr}}$ between experimental observations and numerical predictions are summarized in Table 3 , and the $U_{\mathrm{cr}}$ of experimental observations agree well with the results of CFD simulation. Moreover, the static coefficients comparison of twinbox girders with various VCS between the wind tunnel tests and CFD simulation were presented in Fig.8. For three representative cases of S02_A00, S02_A06 and S02_A08, the static coefficients of experimental results are close to those of CFD simulation, which further show that the CFD simulation are reasonable.

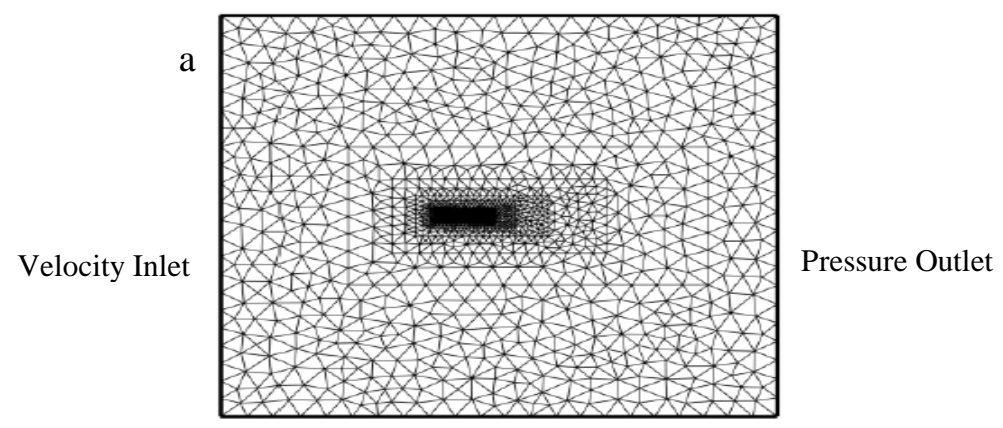

b

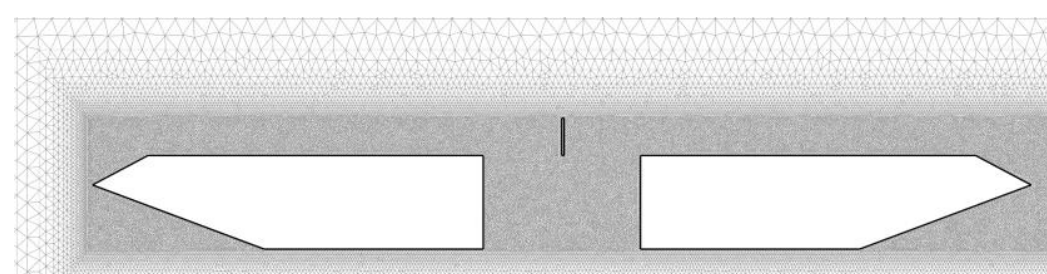

Fig. 7. Overview of computational region: (a) The whole computational region, (b) zoom around the girder section

340 Table 3

341 Comparison $\mathrm{U}_{\mathrm{cr}}$ obtained from wind tunnel tests and CFD simulation

\begin{tabular}{|c|c|c|c|c|c|}
\hline Case & $\begin{array}{c}\text { Experimental } \\
\text { (unit: } \mathrm{m} / \mathrm{s} \text { ) }\end{array}$ & $\begin{array}{c}\text { CFD } \\
\text { (unit: } \mathrm{m} / \mathrm{s} \text { ) }\end{array}$ & Case & $\begin{array}{c}\text { Experimental } \\
\text { (unit: } \mathrm{m} / \mathrm{s} \text { ) }\end{array}$ & $\begin{array}{c}\text { CFD } \\
\text { (unit: } \mathrm{m} / \mathrm{s} \text { ) }\end{array}$ \\
\hline
\end{tabular}




\begin{tabular}{|l|c|c|c|c|c|}
\hline S02_A00 & 15.5 & 15.4 & S04_B04 & 18.4 & 18.8 \\
\hline S02_A06 & 19.5 & 19.2 & S02_AC04 & 22.3 & 22.0 \\
\hline S02_A08 & 14.8 & 15.0 & S04_BC04 & 19.9 & 20.2 \\
\hline S08_A04 & 15.8 & 16.2 & & & \\
\hline
\end{tabular}

342

343
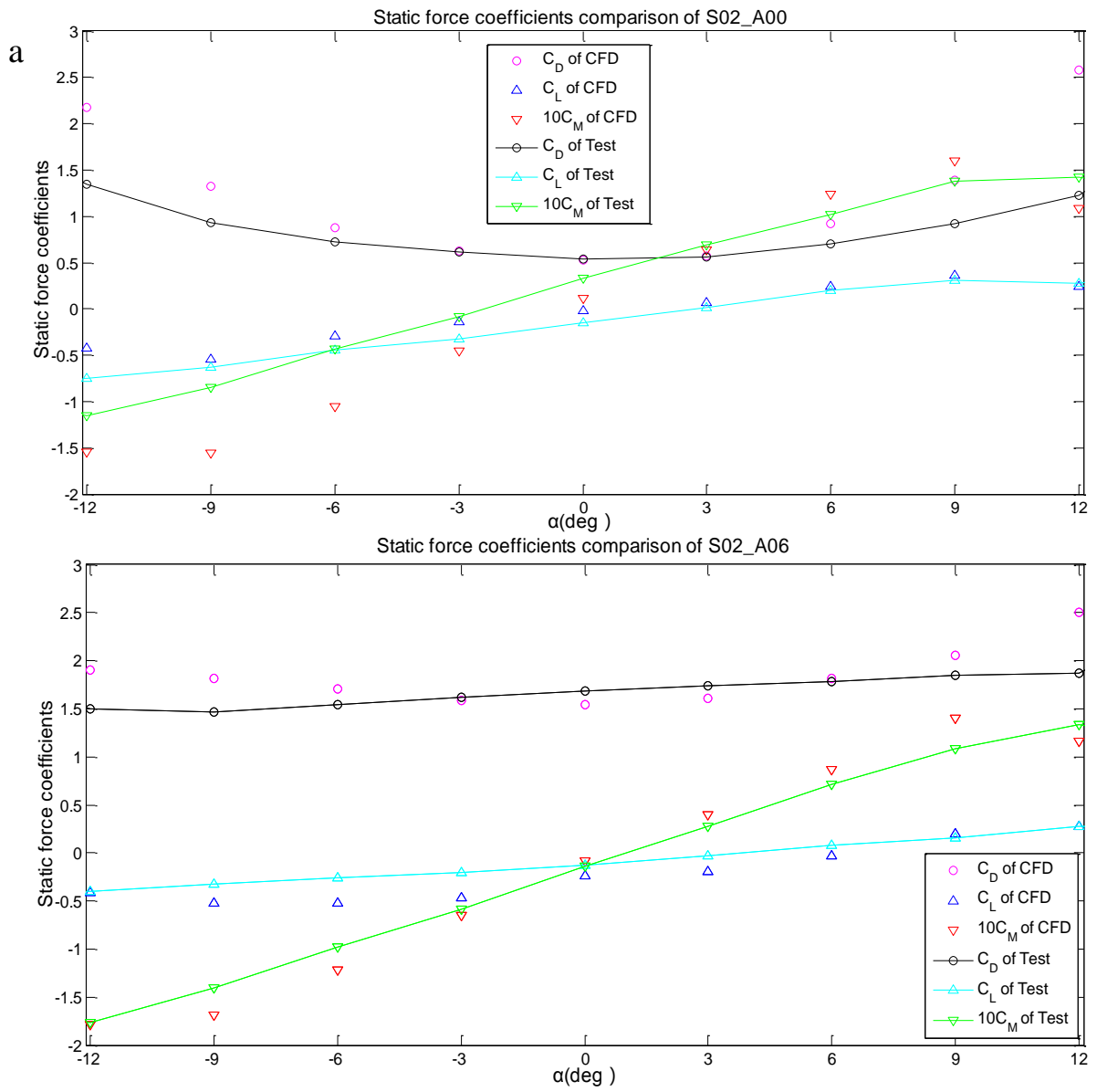


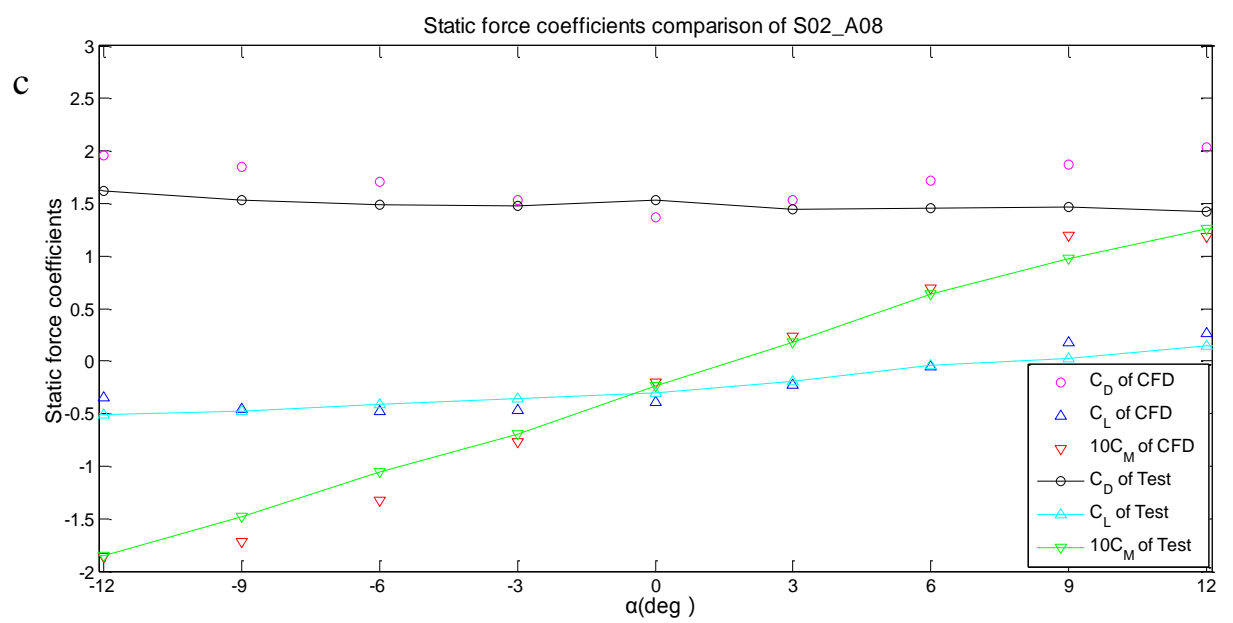

\subsection{Velocity fields comparison}

Fig. 9 shows the velocity vector maps of some typical testing cases of twin-box 349 girders with VCS under the $+3^{\circ}$ wind attack angle when the structure undergoes the flutter 350 onset.

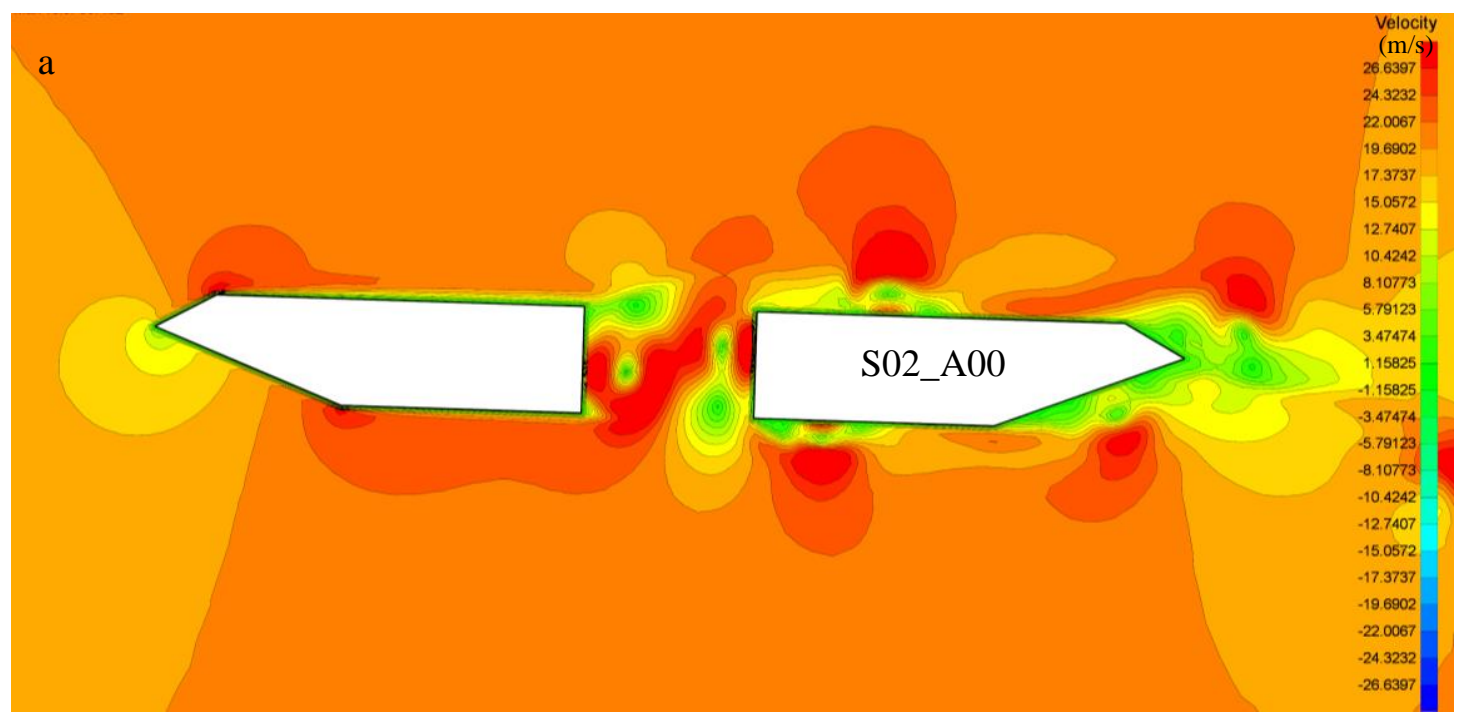




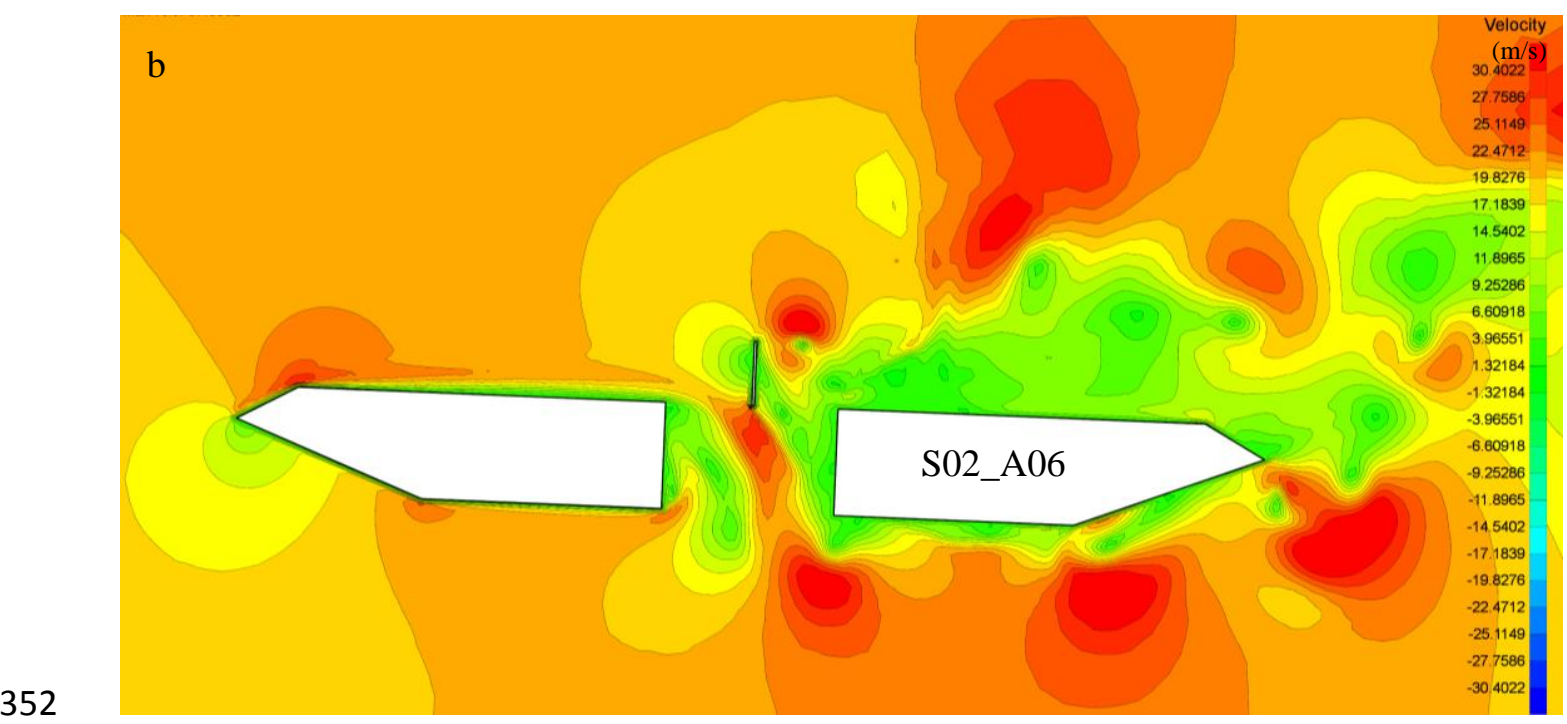

352

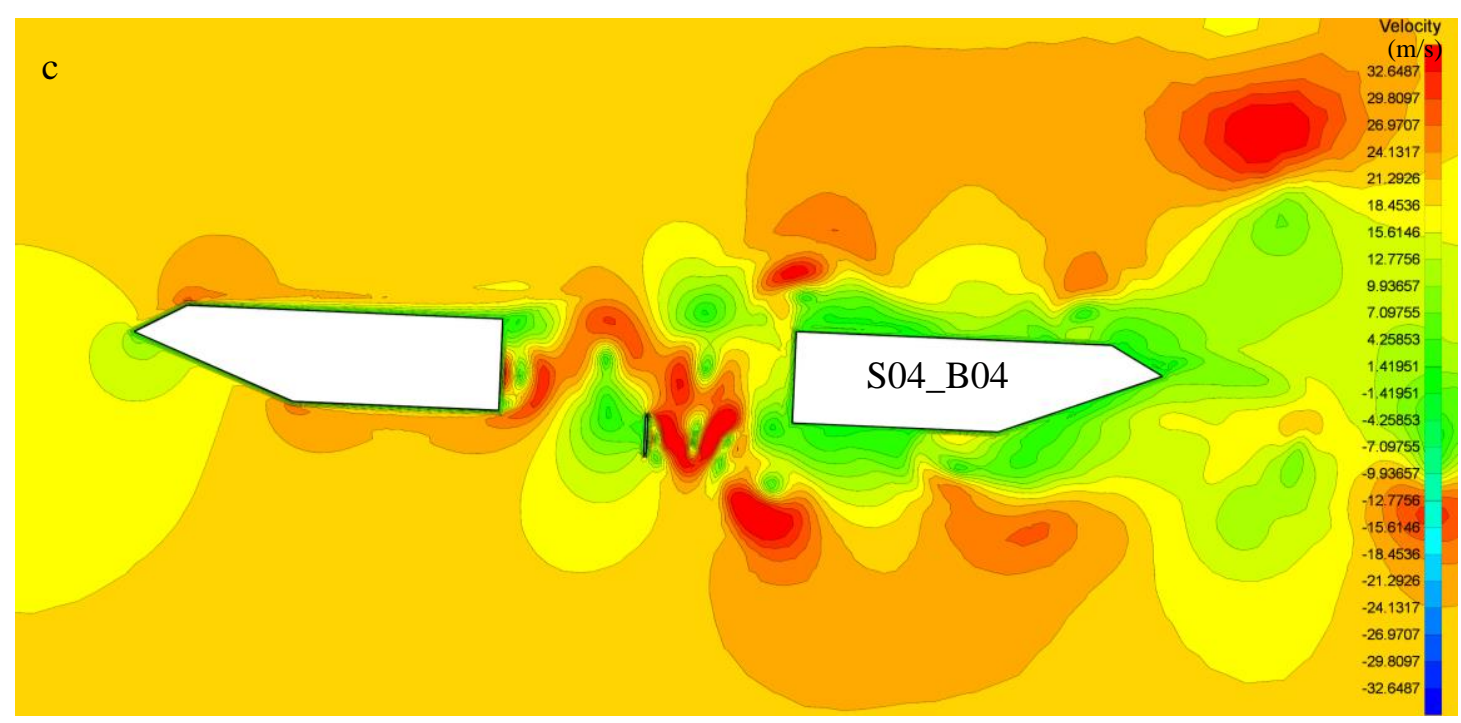

353

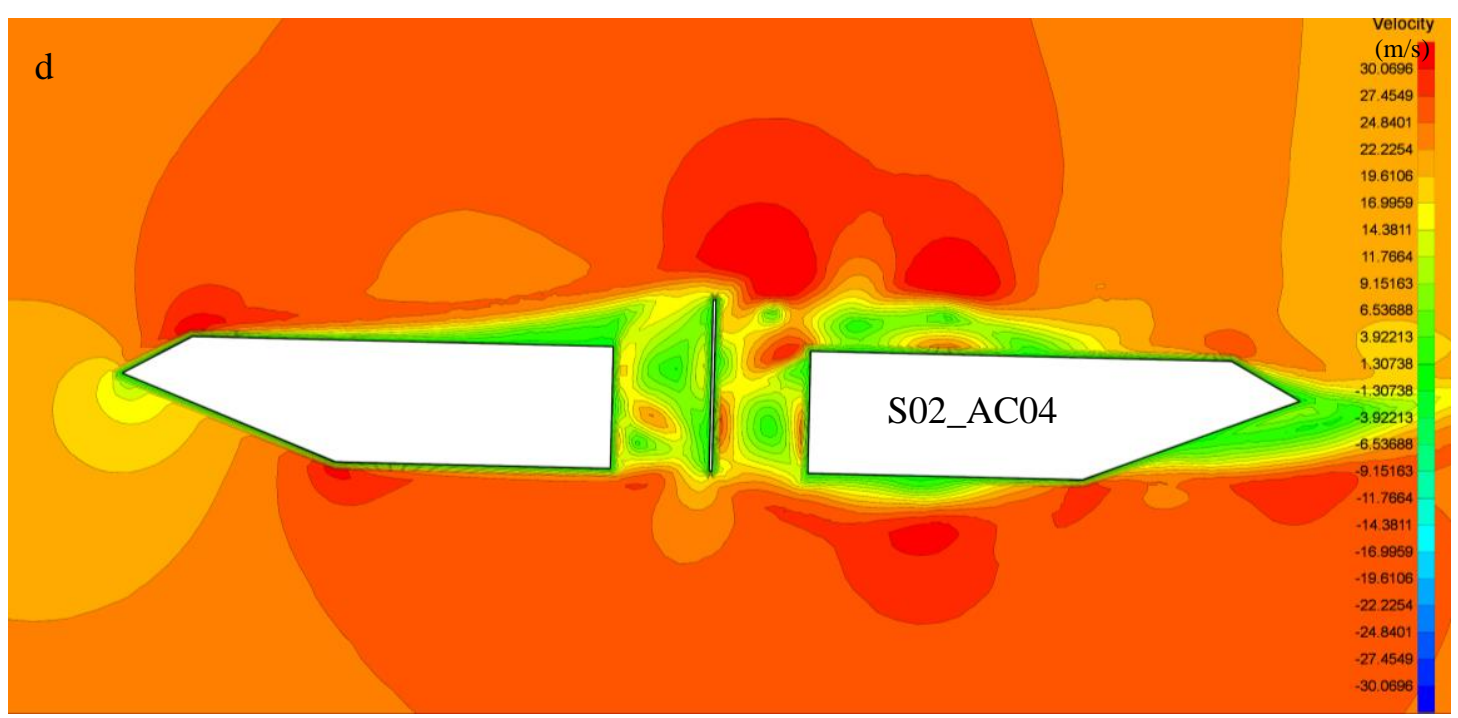




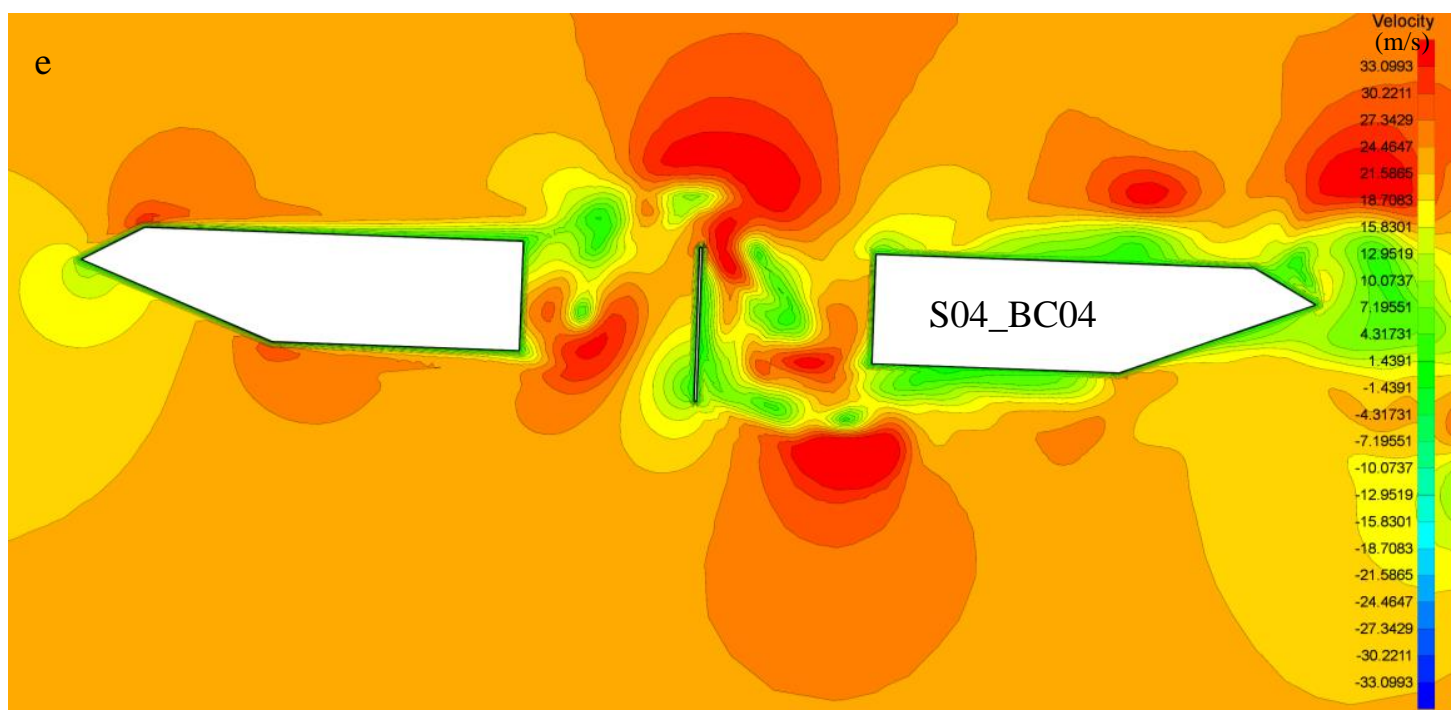

355

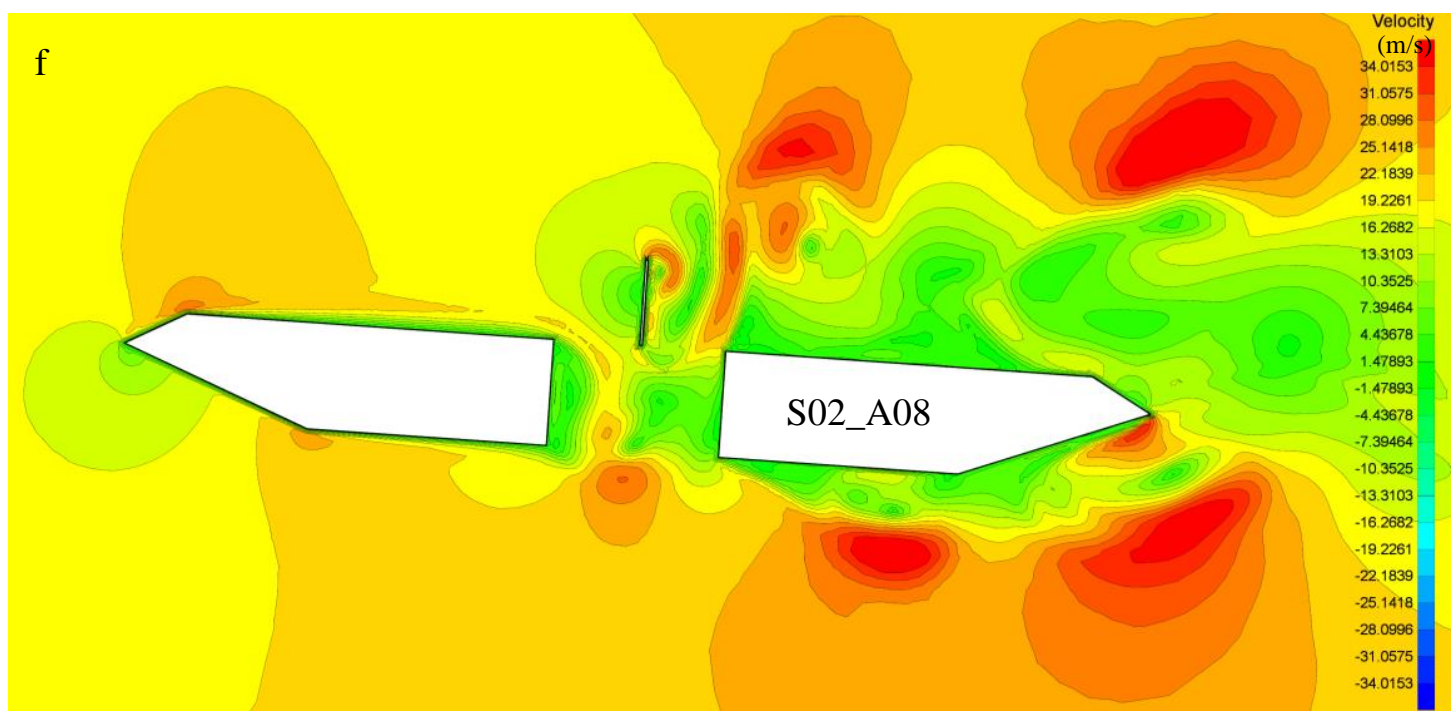

356

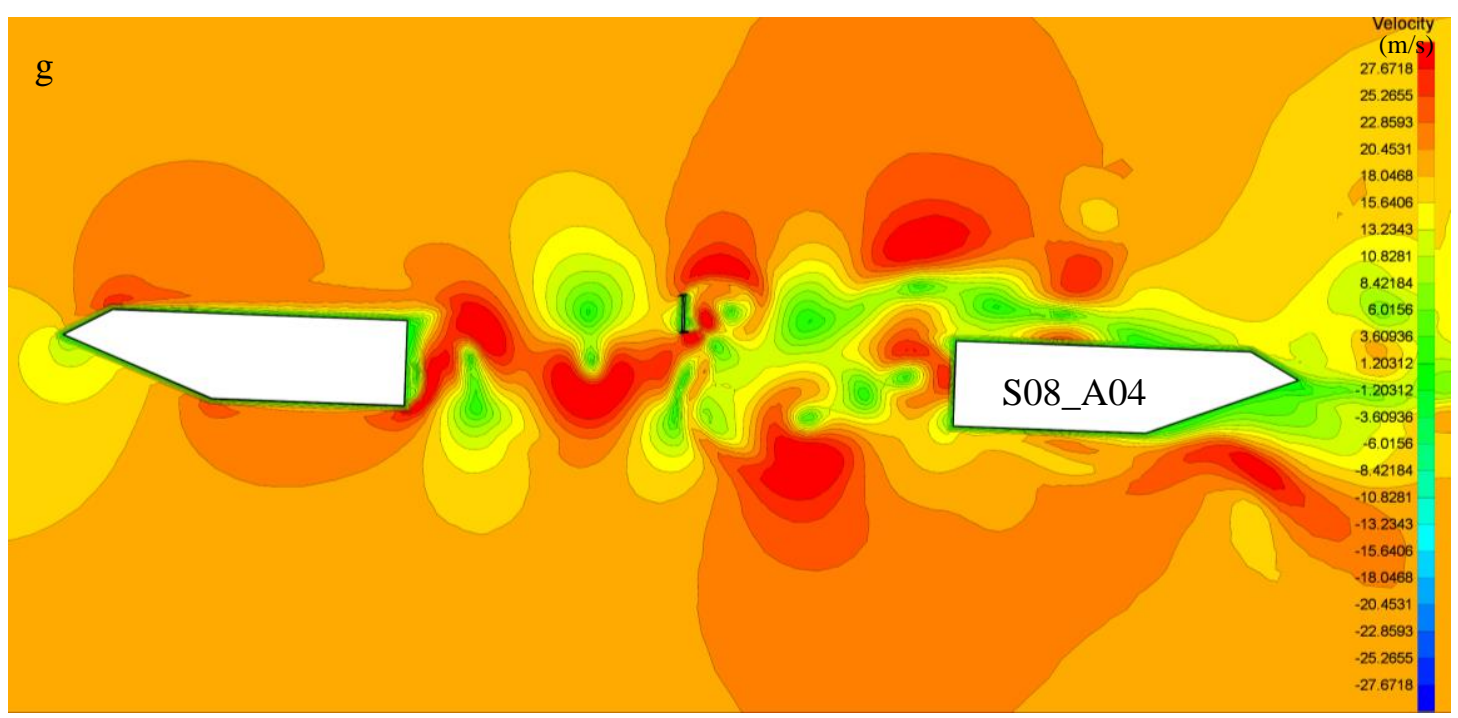


Fig.9 Instantaneous velocity maps: (a) S02_A00, (b) S02_A06, (c) S04_B04, (d) S02_AC04, (e)

$$
\text { S04_BC04, (f) S02_A08, and (g) S08_A04 }
$$

The simulation results show that there is a significant change in the flow structures under the central slotting and round the leeward girder after installing the VCS. The 362 comparison of the fluctuating velocity field of Type A and Type AC (or Type B and Type 363 BC) shows that the VCS under the central slotting could potentially inhibit the formation 364 of large vortices around the surface of the leeward girder. Meanwhile, only small vortices

365 are generated in the rear of the VCS for Type A and Type B, while large vortices appear in 366 most regions of the central slotting and completely isolated by the VCS for Type AC and 367 Type BC.

368 Although the large vortices in central slotting could be found in the rear of the VCS 369 with the $0.8 \mathrm{~h} / \mathrm{H}$ (Type A), they only appear in relatively small areas, which are far away 370 from the upper surface of the leeward girder (Fig. 9(f)). With the increase of SWR, large 371 vortices gradually occupy most of the central slotting area of a twin box with $80 \%$ SWR, 372 and the vortices in the rear of the Type A are alternated with other vortices under the central 373 slotting. The comparison of Fig. 9(a), (b),(d) and (f) shows that, for the $20 \%$ SWR without 374 VCS, large vortices could appear under the central slotting, around the surface and the wind 375 fairing of the leeward girder. In summary, the VCS have significant impact on the flutter 376 performance of twin-box girders through altering the vortices' structures under the central 377 slotting and around the leeward girder.

\subsection{Comparison of pressure distribution}

Fig. 10 compared the corresponding pressure distributions around the girders of the above mentioned cases (Fig.9) at the flutter onset. The red and the blue vortices denote the largest positive and negative pressure amplitude, respectively. 


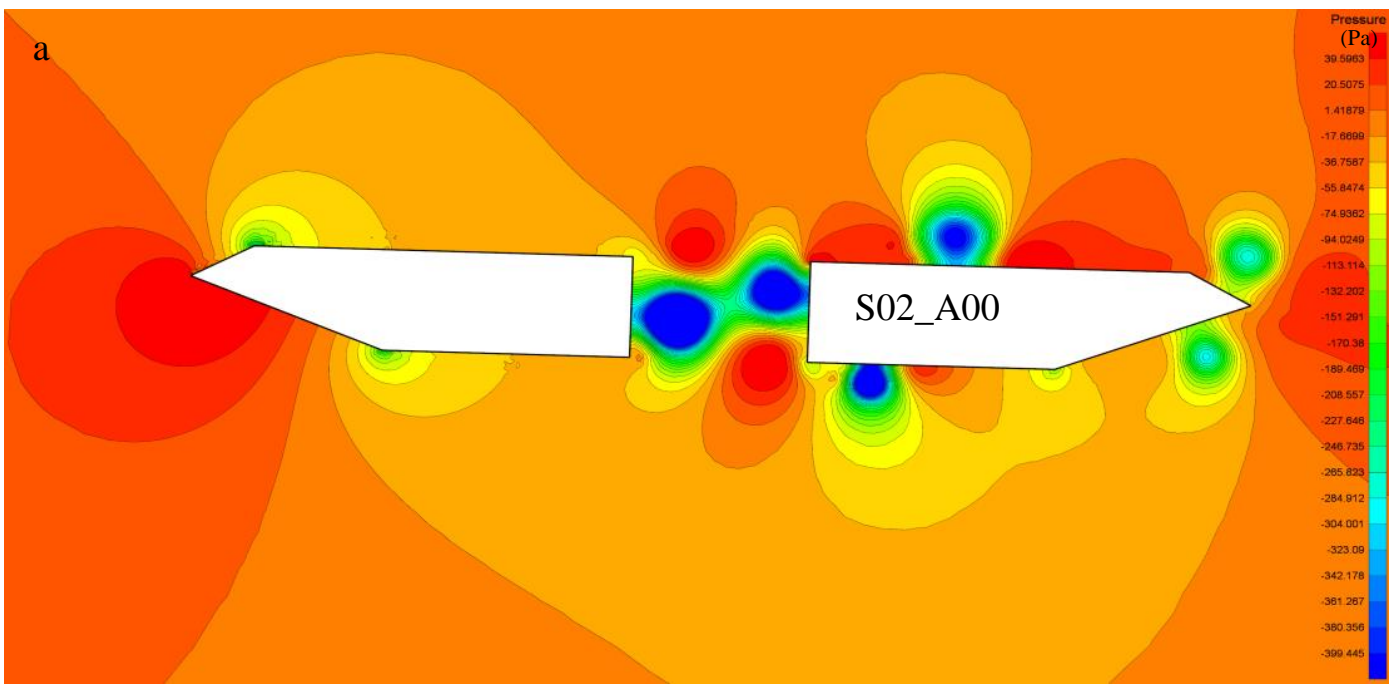

383
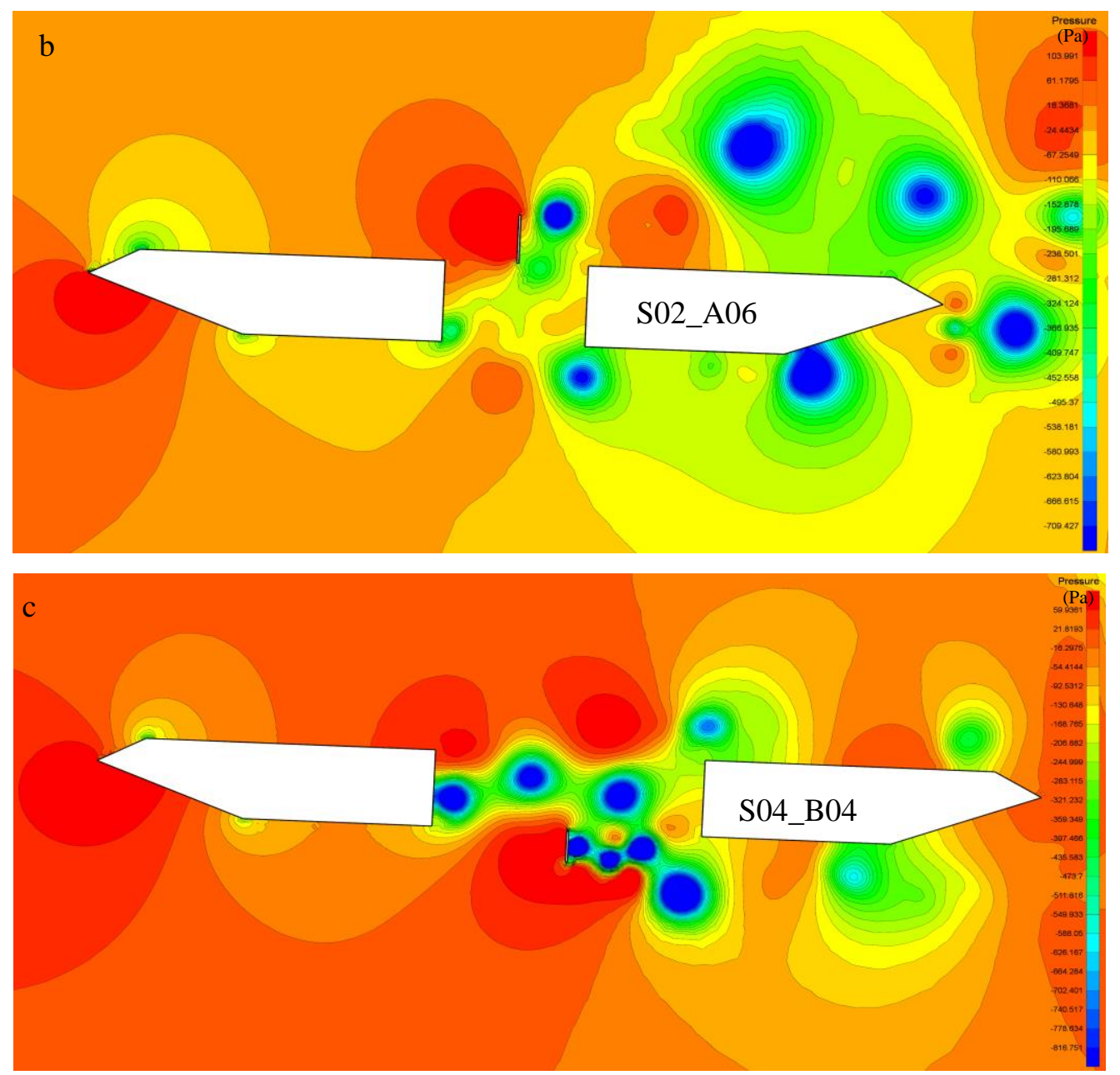


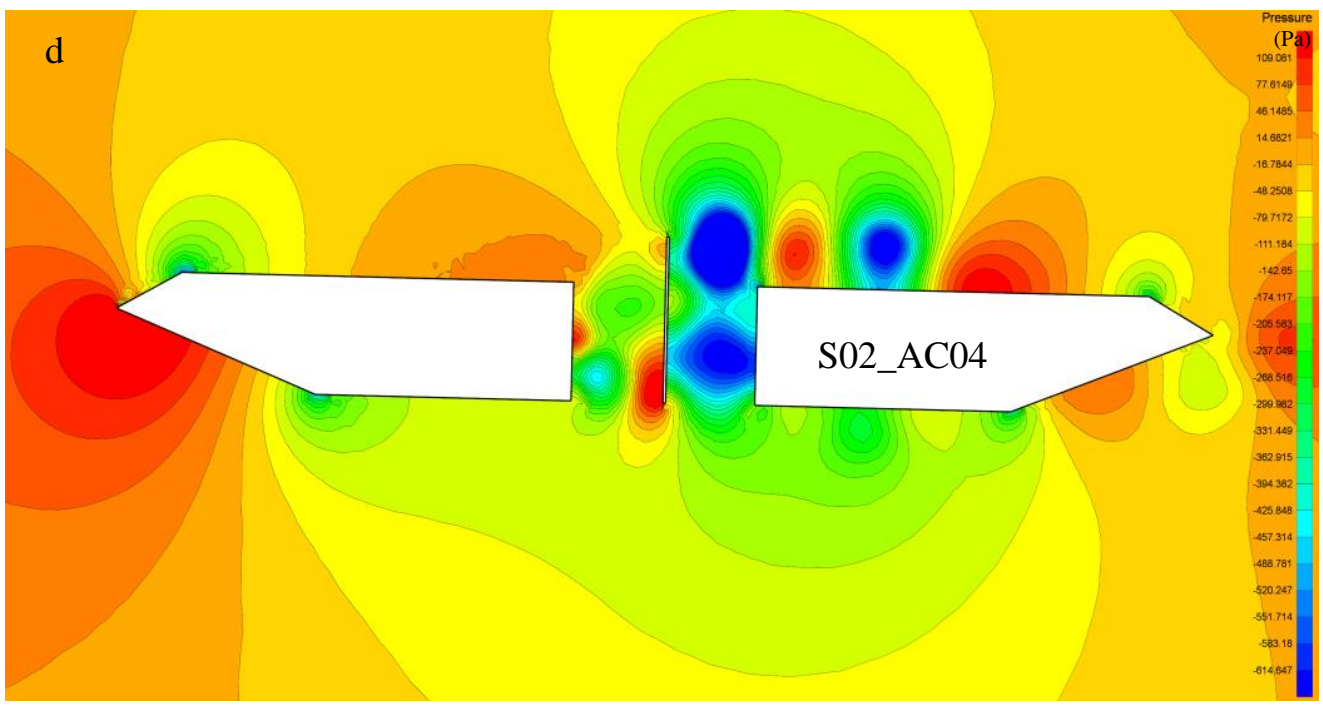

386
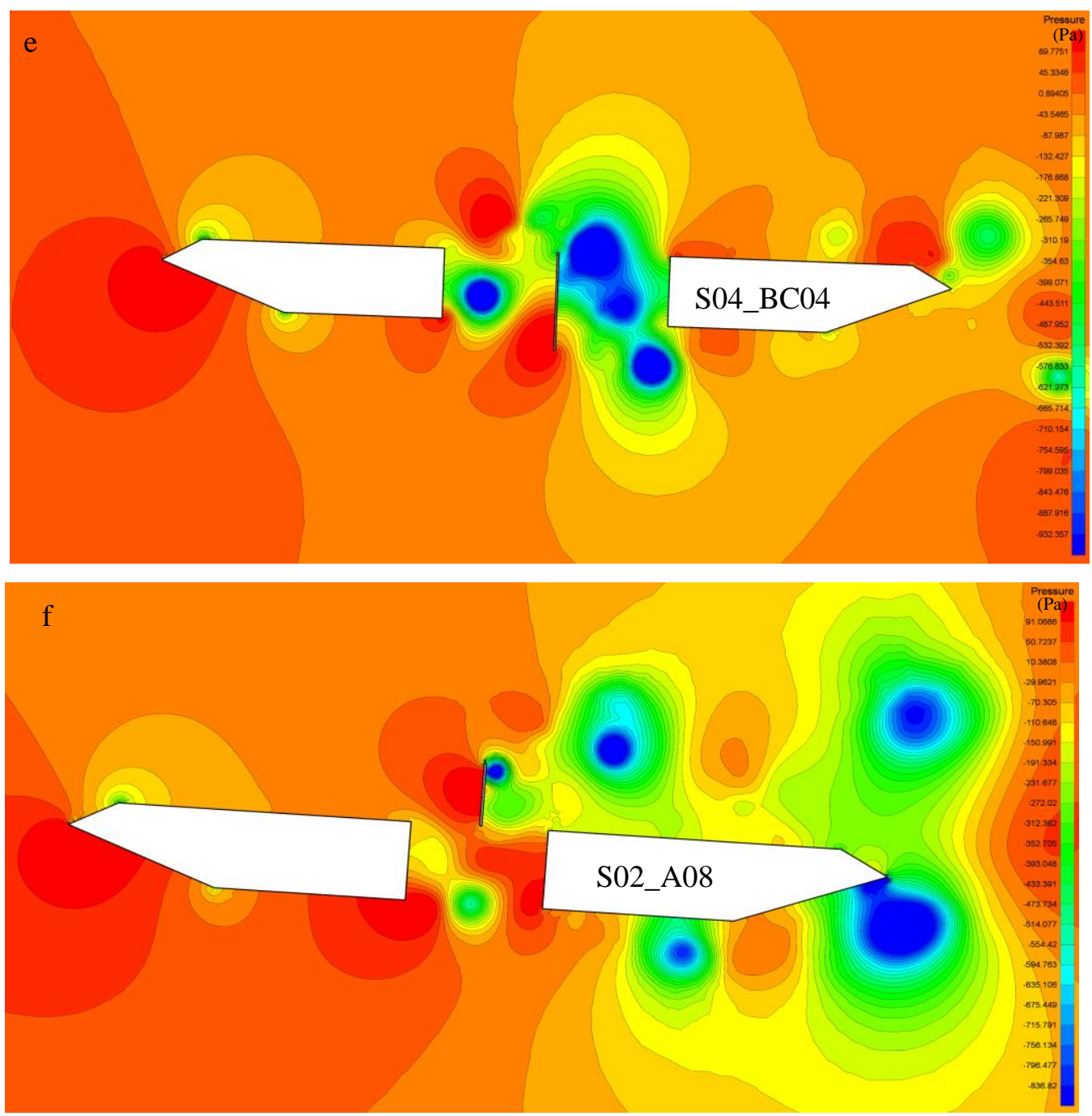


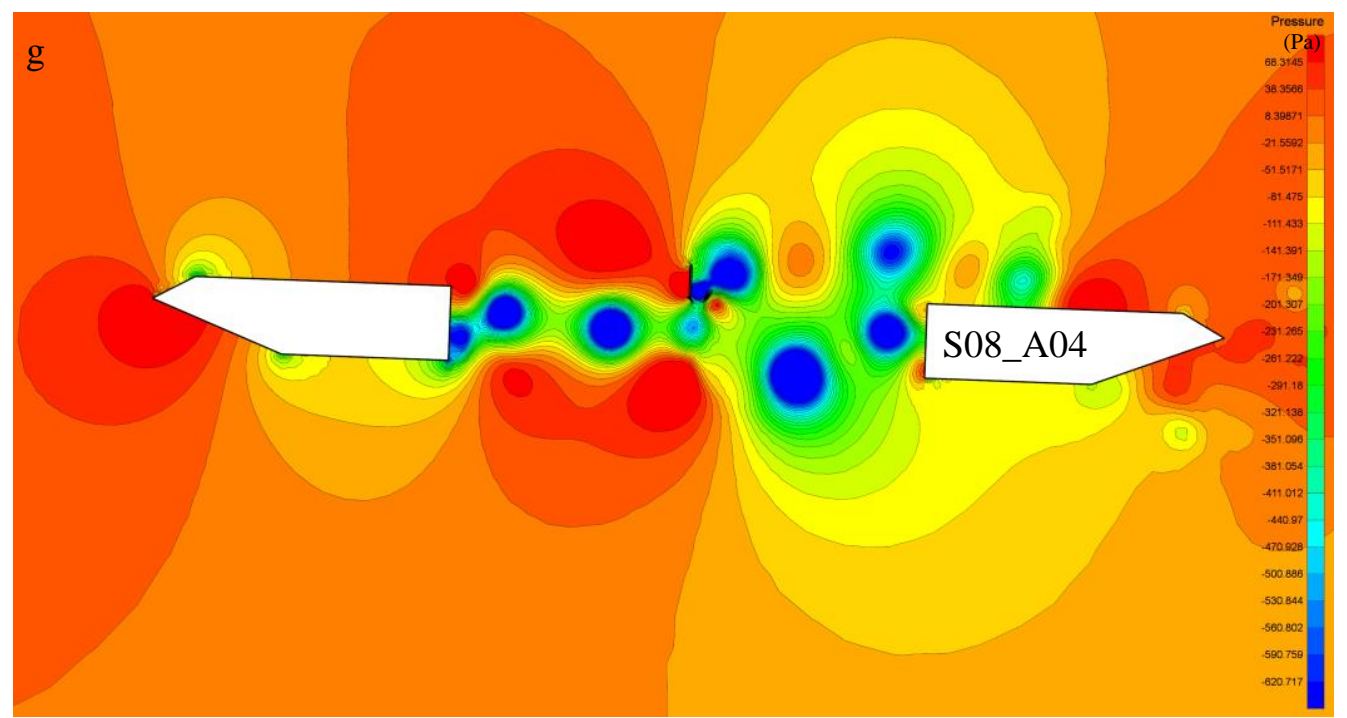

Fig. 10. Surface pressure around girder section: (a) S02_A00, (b) S02_A06, (c) S04_B04, (d) S02_AC04, (e)

$$
\text { S04_BC04, (f) S02_A08, and (g) S08_A04 }
$$

Fig.10 demonstrates that the installation of VCS has great influence on the pressure distributions under the central slotting and round the leeward girder of a twin-box girder. Nevertheless, the change of instantaneous pressure distribution of the windward girder could be neglected and large positive pressure always happens at the bottom edge of the wind fairing of the windward girder. It can be seen that larger negative pressures appear in the rear of VCS. Both the Type A and Type AC mainly affect the pressure distribution of the upper surface of the leeward girder, while the pressure distribution of the lower surface of the leeward girder have change significantly after installing the Type B or Type BC. In addition, the region with negative pressure distribution under the central slotting becomes smaller for the twin-box girder, regardless of the Type A and Type B.

The large negative pressures rarely happen under the central slotting of the twin-box girder with the $0.8 \mathrm{~h} / \mathrm{H}$ VCS (Type A). However, the large negative pressures appear at the upper surface and beneath the wind fairing of the windward girder. Fig. 9(g) and Fig. 10(g) show the velocity and pressure distribution of $80 \%$ SWR with the $0.4 \mathrm{~h} / \mathrm{H} \mathrm{VCS}$, respectively. The comparison results show that most of the regions in the front of the VCS under the central slotting of a twin box with $80 \%$ SWR are subjected to high positive 408 Therefore, the large vortex structures could potentially lead to the formation of negative 
pressure zone under the central slotting and round the leeward girder. The transformation

410 of pressure distribution owing to the installation of VCS determine the effect of the 411 aerodynamic forces on the girder section, ultimately modify the flutter instability 412 performance of the twin-box girder.

\section{5. The development of modified Selberg formula}

\section{$414 \quad 5.1$ Empirical expression}

415 Selberg formula is widely utilized to calculate the critical flutter wind speed of 416 streamlined cross sections for design purpose [29]. A modified Selberg formula was further 417 developed to calculate the $\mathrm{U}_{\mathrm{cr}}$ of a closed box girders with Type A of VCS, wherein Lorentz 418 peak-value function was utilized [8]. Subsequently, the Lorentz peak-value function was 419 also used to estimate the $\mathrm{U}_{\mathrm{cr}}$ of twin-box girders with various SWR [4]. In order to 420 quantitatively evaluate the control effects of VCS on the flutter performance of twin-box 421 girders with various SWR, both the Lorentz peak-value function and Sine function were 422 used to estimate the $\mathrm{U}_{\mathrm{cr}}$ in this study. The $\mathrm{U}_{\mathrm{cr}}$ of twin-box girders with different $\mathrm{h} / \mathrm{H}$ ratios 423 and types of VCS could be estimated by using a correction coefficient of $\eta_{C S}$. Based on 424 the correction coefficient $\eta_{T B}$ of twin-box girders with various SWR (Eq.3), the revised 425 critical flutter wind speed $U_{c r}^{T B C S}$ of twin-box girders with various SWR and VCS (Eq.2) 426 may be predicted from a modified Selberg formula. Both the Lorentz peak-value function 427 and Sine function of $\eta_{C S}$ were fitted to the measured $U_{c r}$ in the case of the angle of attack 428 of $+3^{\circ}$ using the nonlinear least squares method, as shown in Eq.4 and Eq.5, respectively.

$$
\begin{gathered}
U_{C r}^{T B C S}=\eta_{T B} \eta_{C S} K B f_{\alpha}\left\{\frac{m r}{\rho B^{3}} \times\left[1-\left(\frac{\omega_{h}}{\omega_{\alpha}}\right)^{2}\right]\right\}^{1 / 2} \\
\eta_{T B}=0.91+\frac{0.12}{0.4+4 \times\left(0.48-D / B_{S}\right)^{2}} \\
\eta_{C S}^{L}=a_{1}+\frac{a_{2}}{a_{3}+4 \times\left(\frac{h}{H}-a_{4}\right)^{2}} \\
\eta_{C S}^{S}=a_{1}+a_{2} \times \sin \left(a_{3} \times\left(\frac{h}{H}\right)+a_{4}\right)
\end{gathered}
$$

433 where $\eta_{T B}$ is correction coefficient of the $U_{c r}$ of twin-box girders and basic box girders $434\left(0 \%\right.$ SWR), as reported in the study of Yang et al [10]; $\eta_{C S}$ is correction coefficient of the 
$435 U_{c r}$ of twin-box girders with VCS; the $m$ is the effective mass per unit span; $r$ is the mass 436 radius of gyration; $\omega_{h}$ and $\omega_{\alpha}$ are the circular frequencies of the vertical and torsional 437 modes, respectively; $\rho$ is air density; $D / B_{s}$ is slot width ratio; and $K$ is shape factor of 438 sectional model with $\mathrm{K}=4-8.37 \times\left(\frac{H}{B}\right)^{0.766} ; \eta_{C S}^{L}$ and $\eta_{C S}^{S}$ are using the Lorentz function 439 and Sine function, respectively. As shown in Eq. (3) to (5), the $\eta_{\text {тв }}$ is correction 440 coefficient of the $U_{c r}$ of twin-box girders which is related to the critical factor of slot 441 width ratio $D / B_{s}$, while $\eta_{c S}$ is correction coefficient of the $U_{c r}$ of twin-box girders with 442 VCS which is related to the critical factor of relative height (i.e. $h / H$ ) of VCS.

\subsection{Comparison of correction coefficient}

$444 \quad$ The correction coefficient $\left(\eta_{C S}^{L}\right.$ and $\eta_{C S}^{S}$ ) of twin-box girders with four types of VCS 445 using Lorentz function and Sine function were calculated according to the testing cases of 446 Table 2. The typical cases of four types of VCS by two functions were compared at the 447 angle of attack of $+3^{\circ}$ in Fig. 10, and the specific parameters of $\eta_{C S}^{S}$ for five SWR by Sine 448 function are listed in the Table 4.

449 By comparing all the $\eta_{C S}$ fitted by Lorentz function and Sine function, it can be 450 found that the fitted $\eta_{C S}^{L}$ has maximum value of 1.258 when the SWR is $20 \%$ and the h/H 451 ratio of VCS is 0.6 for Type $\mathrm{A}$, and a minimum value of 0.709 when the $\mathrm{h} / \mathrm{H}$ ratio 452 approaches 1.0. As shown in Fig. 11(a) and (b), for $60 \%$ SWR, there is a difference in the 453 fitting curves by using the Lorentz function and Sine function, where the largest residual 454 of the Lorentz function and Sine function are $1.2 \%$ and $-0.8 \%$, respectively. The fitting 455 curves of $\eta_{C S}$ for Type B using the Lorentz function are similar to those using the Sine 456 function, expect for the $20 \%$ SWR. All the $\eta_{C S}$ for Type B were fitted reasonably well by 457 these two functions and the largest residual value of Type B is $1.76 \%$ at the $80 \%$ SWR. 458 The largest residual value of the $40 \%$ SWR for Type AC reduces to $-8.794 \%$ using Lorentz 459 function and $-4.22 \%$ using Sine function, respectively. Moreover, the residual value of the 460 Type BC using the Lorentz function (i.e. 5.762\%) is still larger than that using the Sine 461 function (i.e. $3.286 \%$ ).

462 All the largest residual values of $\eta_{C S}$ fitted by the Sine function are smaller than 5\%, 463 as shown in the Table 4. In particular, the largest residual values of the $20 \%$ SWR with 
464 Type B using the Lorentz function and Sine function are 3.0\% and 6.2\%, respectively. It is 465 found that only the Lorentz function could perfectly describe the relationship of different 466 heights of VCS and $\eta_{C S}$ of the $20 \%$ SWR, since its distribution is more likely to be a singly 467 peaked function. Therefore, the Lorentz peak-value function is not suitable for the case of 468 twin-box girders with various SWR and VCS (expect for the 20\% SWR of Type B), and 469 the fitted function of correction coefficient based on the Sine function agrees reasonably 470 well with the change in characteristic of the $U_{c r}$ under various schemes of VCS.
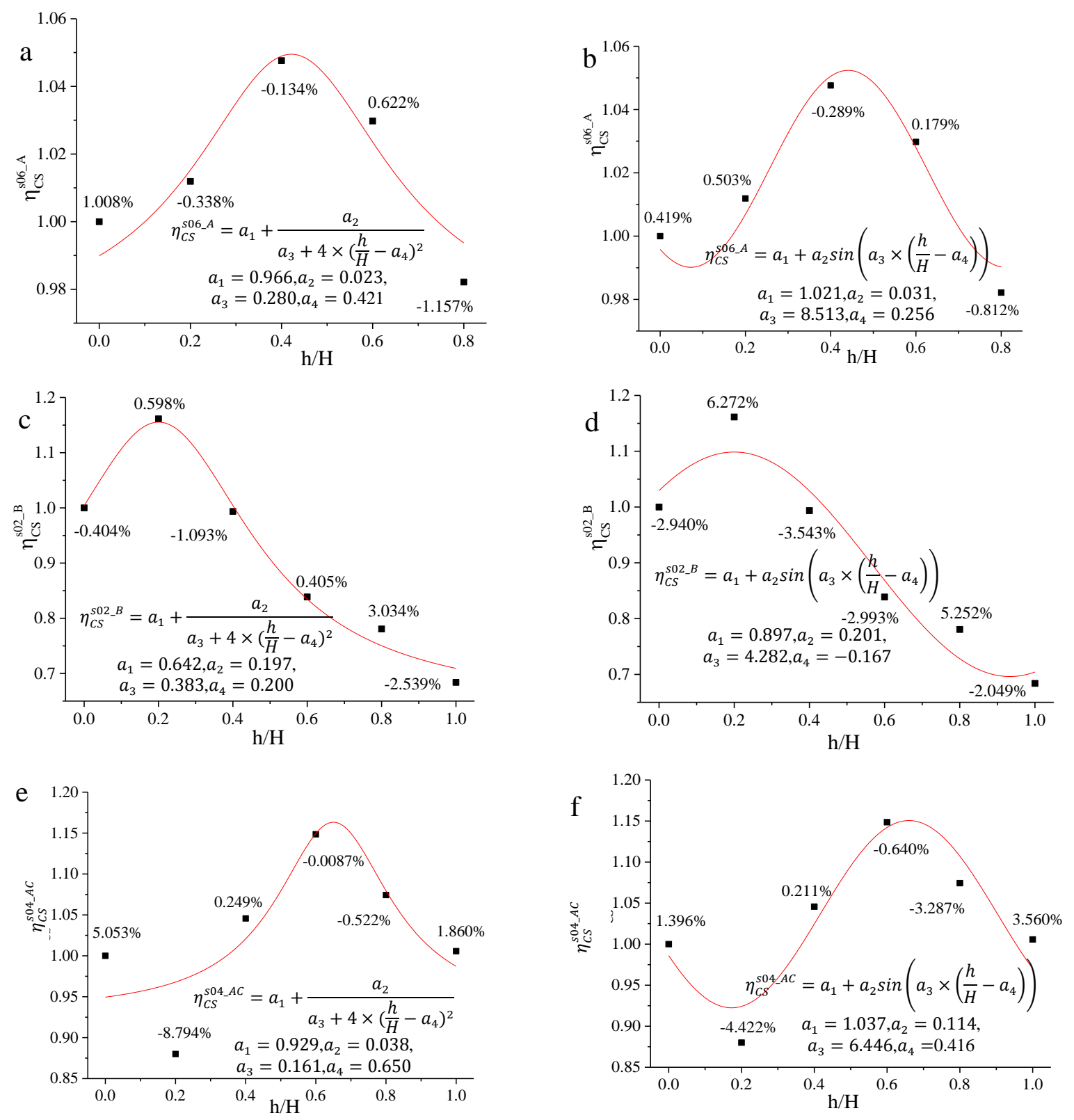

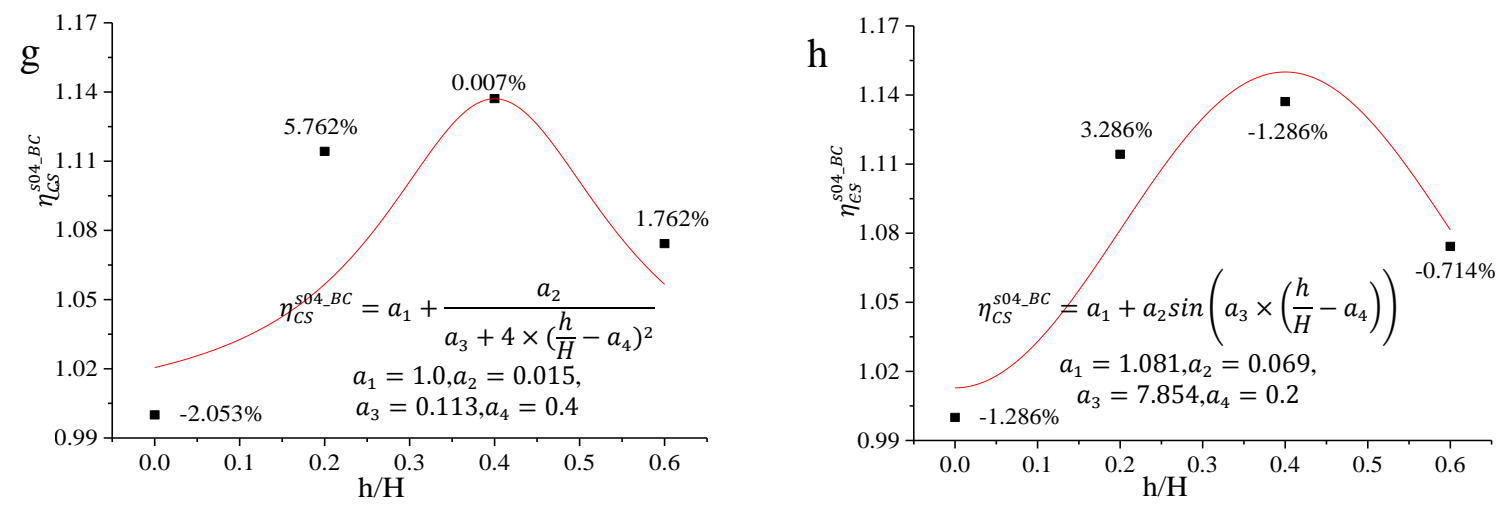

Fig. 11. Correction coefficient $\eta_{C S}$ of four types: (a) Lorentz function of $60 \%$ slot ratio with Type A, (b) Sine function of $60 \%$ slot ratio with Type A, (c) Lorentz function of $20 \%$ slot ratio with Type B, (d) Sine function of $20 \%$ slot ratio with Type B, , (e) Lorentz function of $40 \%$ slot ratio with Type AC, (f) Sine function of $40 \%$ slot ratio with Type AC, (g) Lorentz function of $40 \%$ slot ratio with Type BC, and (h) Sine function of $40 \%$ slot ratio with Type BC.

\section{Table 4}

Parameters of correction coefficient $\eta_{C S}$ by Sine function

\begin{tabular}{|c|c|c|c|c|c|c|c|}
\hline Type & $\mathrm{D} / \mathrm{B}_{\mathrm{s}}$ & $\eta_{C S}$ & $a_{1}$ & $a_{2}$ & $a_{3}$ & $a_{4}$ & $\begin{array}{l}\text { Largest } \\
\text { residual }\end{array}$ \\
\hline \multirow{5}{*}{ A } & $20 \%$ & $\eta_{C S}^{S 02 \_A}$ & 1.123 & 0.159 & 7.814 & 0.282 & $-4.257 \%$ \\
\hline & $40 \%$ & $\eta_{C S}^{S 04 \_A}$ & 0.281 & 0.802 & 1.524 & -0.717 & $2.082 \%$ \\
\hline & $60 \%$ & $\eta_{C S}^{S 06 \_A}$ & 1.021 & 0.031 & 8.513 & 0.256 & $-0.812 \%$ \\
\hline & $80 \%$ & $\eta_{C S}^{S 08 \_A}$ & 0.900 & 0.112 & 2.041 & -0.524 & $0.623 \%$ \\
\hline & $100 \%$ & $\eta_{C S}^{S 10 \_A}$ & 0.988 & 0.033 & 3.775 & -0.098 & $-1.065 \%$ \\
\hline \multirow{5}{*}{ B } & $20 \%$ & $\eta_{C S}^{S 02 \_B}$ & 0.897 & 0.201 & 4.282 & -0.167 & $6.272 \%$ \\
\hline & $40 \%$ & $\eta_{C S}^{S 04 \_B}$ & 1.03 & 0.0257 & 7.854 & 0 & $2.143 \%$ \\
\hline & $60 \%$ & $\eta_{C S}^{S 06 \_B}$ & 1.007 & 0.055 & 4.254 & 0.049 & $0.716 \%$ \\
\hline & $80 \%$ & $\eta_{C S}^{S 08 \_B}$ & 1.025 & 0.025 & 6.014 & 0.244 & $-1.245 \%$ \\
\hline & $100 \%$ & $\eta_{C S}^{S 10 \_B}$ & 0.985 & 0.077 & 2.650 & -0.077 & $0.454 \%$ \\
\hline
\end{tabular}




\begin{tabular}{|c|c|c|c|c|c|c|c|}
\hline \multirow{3}{*}{$\mathrm{AC}$} & $20 \%$ & $\eta_{C S}^{S 02_{\_} A C}$ & 1.251 & 0.225 & 6.980 & 0.290 & $3.316 \%$ \\
\cline { 2 - 8 } & $40 \%$ & $\eta_{C S}^{S 04_{\_} A C}$ & 1.037 & 0.114 & 6.446 & 0.416 & $4.422 \%$ \\
\hline \multirow{2}{*}{$\mathrm{BC}$} & $20 \%$ & $\eta_{C S}^{S 02_{-} B C}$ & 1.055 & 0.158 & 7.854 & 0 & $4.194 \%$ \\
\cline { 2 - 8 } & $40 \%$ & $\eta_{C S}^{S 04 \_B C}$ & 1.081 & 0.069 & 7.854 & 0.2 & $3.286 \%$ \\
\hline
\end{tabular}

471

472

473

474

475

476

477

478

479

480

481

482

483

484

485

486

487

488

489

490

491

492

\section{Conclusions}

In this study, the flutter characteristics of twin-box girders bridges with the combination schemes of various slot width ratios and vertical central stabilizers were studied through experimental investigation in conjunction with theoretical analysis. The major conclusions are as follows:

- The height variation of VCS significantly affects the $U_{c r}$ and $\beta$ of a twin-box girder bridge with $20 \%$ SWR. However, under a relatively large SWR (e.g. >60\%), the change of the height of VCS has little impact on the flutter stabilization. Besides, among four types, Type $\mathrm{AC}$ and Type $\mathrm{BC}$ is the best choice of the flutter performance for the $20 \%$ SWR and $40 \%$ SWR, respectively.

- Using 2D-3DOF analysis, we demonstrated that aerodynamic damping Part A with reference of flutter derivative $\mathrm{A}_{2}{ }^{*}$ makes the greatest contribution to the flutter instability for a VCS with a h/H ratio of 0.8 , while the role of Part D with reference of $\mathrm{A}_{1}{ }^{*} \mathrm{H}_{3}{ }^{*}$ becomes critical for a relatively short VCS (i.e. $\mathrm{h} / \mathrm{H}$ is less than 0.2 ). In addition, the increase of heaving DOF participation level with the VCS with an optimal h/H ratio of 0.4 leads to a higher $\mathrm{U}_{\mathrm{cr}}$.

- The results from computational Fluid Dynamics (CFD) simulations indicate that the geometry and position of VCS could potentially change the evolution of vortices' structures and pressure distribution under the central slotting, and so affect the flutter performance.

- The proposed modified Selberg formula based on the Sine function has the capability of predicting the $U_{c r}$ of twin-box girders with various SWRs and VCS. 
It should be mentioned that further investigation of stabilization mechanism of VCS 494 are required in order to fundamentally understand the critical factors (e.g. the flow 495 structures, aerodynamic forces and structural responses). In addition, future research work 496 should focus on the overall aerodynamic performance of twin-box girders bridges with 497 vertical central stabilizers (e.g. stationary aerodynamic performance, vortex-induced 498 vibration and buffet performance).

\section{Acknowledgments}

The authors gratefully acknowledge the support for the research work jointly 501 provided by the National Key Basic Research Program of China (973 Program) (No. 502 2013CB036300), the National Science Foundations of China (No.91215302, 51078276, 503 and 51678436).

\section{References}

505 [1] Sato H, Hirahara N, Fumoto K, Hirano S. and Kusuhara S. Full aeroelastic model test of a super long-span bridge with slotted box girder. J Wind Eng Ind Aerodyn 2002;90:2023-2032.

[2] Yang YX, Zhou R, Ge YJ, Zhang LH. Experimental studies on VIV performance and countermeasures for twin-box girder bridges with various slot width ratios. J Fluid Struct, 2016;66:476-489.

[3] Trein CA, Shirato HM, Matsumoto M. On the effects of the gap on the unsteady pressure characteristics of two-box bridge girders. Eng Struct 2015;82(1):121-133.

[4] Yang YX, Zhou R, Ge YJ, Mohotti D, Mendis P. Aerodynamic instability performance of twinbox girder for long-span bridges. J Wind Eng Ind Aerodyn 2015;145:196-208.

[5] Miranda SD, Parruno L, Ricci M, Ubertini F. Numerical study of a twin box bridge deck with increasing gap ratio by using RANS and LES approaches. Eng. Struct, 2015;99(15):546-558.

[6] Andersen MS, Johansson J, Brandt A, Hansen SO. Aerodynamic stability of long span suspension bridges with low torsional natural frequencies. Eng Struct 2016; 120(1):82-91.

[7] Ueda T, Yasuda M. Nakagaki, R. Mechanism of aerodynamic stabilization for long-span suspension bridge with stiffening truss-girder. J Wind Eng Ind Aerodyn 2000;33(1-2):333-340. 
[8] Ge YJ, Zou XJ, Yang YX. Aerodynamic stabilization of central stabilizers for box girder suspension bridges. Wind Struct 2009;12(4):285-298.

[9] Chen AR, Zhou ZY, Xiang HF. On the mechanism of vertical stabilizer plates for improving aerodynamic stability of bridges. Wind Struct 2006; 9(1):59-74.

[10] Yang YX, Ge YJ, Xiang HF. Aerodynamic flutter control for typical girder sections of long-span cable-supported bridges. Wind Struct 2009;12, 205-217.

[11] Sato H, Kusuhara S, et al. Aerodynamic characteristics of super long-span bridges with slotted box girder. J Wind Eng Ind Aerodyn 2000;88(2): 297-306

[12] Miyata T. Significance of aero-elastic relationship in wind-resistant design of long-span bridges. J Wind Eng Ind Aerodyn 2002;90:1479-1492.

[13] Fumoto K, Hata K, Matsuda K, Murakami T, Saito Y. and Shirai S. Aerodynamic Improvement of Slotted One-Box Girder Section for Super Long Suspension Bridge. In: Proceedings of the 6th Asia-Pacific Conf. on Wind Engineering, Seoul, Korea; 2005. pp. 1222-1236.

[14] Li YL, An WS, Li CJ, Liao HL, Aerodynamic optimization of three-box-girder deck by CFD method. China Civil Eng J 2013;46(1):.61-68. (In Chinese)

[15] Matsumoto M, Mizunoc K. et al. Flutter instability and recent development in stabilization of structures. J Wind Eng Ind Aerodyn 2007;95(9-11):888-907.

[16] Chen ZQ, Ouyang KJ, Niu HW, Hua XG. Aerodynamic Mechanism of Improvement of Flutter Stability of Truss-girder Suspension Bridge Using Central Stabilizer. China J Highway and Trans 2009;22(6):53-59. (In Chinese)

[17] Shirai S, Ueda T. Aerodynamic simulation by CFD on flat box girder of super-long-span suspension bridge. J Wind Eng Ind Aerodyn 2003;91:279-290.

[18] Bruno L, Khris S. The validity of 2D numerical simulations of vortical structures around a bridge deck. Math Comput Model 2003:37(7): 795-828.

[19] Bruno, Luca, et al. 3D flow around a rectangular cylinder: a computational study. J Wind Eng Ind Aerodyn 2010;98 (6): 263-276.

[20] Bruno L, Salvetti MV, and Ricciardelli F. Benchmark on the aerodynamics of a rectangular 5: 1 cylinder: an overview after the first four years of activity. J Wind Eng Ind Aerodyn 2014;126: 87106.

[21] Starossek U, Aslan H, and Thiesemann L. Experimental and numerical identification of flutter derivatives for nine bridge deck sections. Wind Struct 2009; 12 (6): 519.

[22] Miranda SD, Patruno L, Ubertini F, Vairo G. On the identification of flutter derivatives of bridge decks via RANS turbulence models: Benchmarking on rectangular prisms. Eng Struct 2014; 76: 359-370. 
554 [23] Patruno, L. Accuracy of numerically evaluated flutter derivatives of bridge deck sections using 555 RANS: effects on the flutter onset velocity. Eng Struct 2015; 89: 49-65.

556 [24] Scanlan RH, Tomko JJ. Airfoil and bridge deck flutter dervatives. J Eng Mech 1971;97(6):1717$557 \quad 1737$.

558 [25] Agar, T.J.A. Aerodynamic flutter analysis of suspension bridges by a modal technique. Eng. Struct $559 \quad 1989 ; 11(2): 75-82$.

560 [26] Gu M, Qin XR. Direct identification of flutter derivatives and aerodynamic admittances of bridge 561 decks. Eng Struct 2004; 26 (14) : 2161-2172.

562 [27] Seo D W, Caracoglia L. Estimation of torsional-flutter probability in flexible bridges considering 563 randomness in flutter derivatives. Eng Struct 2011;33 (8) : 2284-2296.

564 [28] Yoshikawa M, Tamura T. LES for wind load estimation by unstructured grid system. In: BBAA 565 VII international colloquium on bluff bodies aerodynamics \& applications. Shanghai, China; 2012. 566 [29] Selberg A. Aerodynamic Effect on Suspension Bridges. Proc. of Int. Symposium on Wind Effects on Buildings and Structures, Teddington, England, 1963;2: 462-486. 